\title{
A comperehensive drug repurposing study for Covid19 treatment: Novel putative DHODH inhibitors show association to Serotonin-Dopamine receptors
}

\author{
Burak Berber $^{1}$ and Osman Doluca ${ }^{2}$ \\ ${ }^{1}$ Department of Biology, Faculty of Science, Eskisehir Technical University, Eskisehir, \\ 26480, Turkey \\ ${ }^{2}$ Department of Biomedical Engineering, Izmir University of Economics, Izmir, 35330, \\ Turkey
}

*Corresponding author: osman.doluca@ieu.edu.tr

\begin{abstract}
DHODH is a key enzyme required for de novo pyrimidine synthesis and it is suggested as a target for Covid19 treatment due to high pyrimidine demand by the virus replication in the infected host cells as well as its proven effect of blocking of cytokine release by the immune cells to prevent inflammation leading to acute respiratory distress. There are a number of clinical trials underway for Covid19 treatment using DHODH inhibitors, however, there are only a small number of known DHODH antagonists available for testing.

Here, we have applied a methodology to identify DHODH antagonist candidates, and compared using in silico target prediction tools. A large set of 7900 FDA-approved and clinical stage drugs obtained from DrugBank were docked against 20 different structures DHODH available in PDB. Drugs were eliminated according to their predicted affinities by Autodock Vina. 28 FDA-approved and 79 clinical trial ongoing drugs remained. The mode of interaction of these molecules were analyzed by repeating docking using Autodock 4 and DS Visualiser. Finally, the target region predictions of 28 FDA approved drugs were determined through PASS and SwissTargetPrediction tools.

Interestingly, the analysis of in silico target predictions revealed that serotonin-dopamine inhibitors could also be potential DHODH antagonists. Our candidates shared a common attribute, a possible interaction with serotonin-dopamin receptors as well as other oxidoreductases, like DHODH. Moreover, the BTK-inhibitor Acalabrutunib and serotonindopamine inhibitor drugs on our list have been found in the literature that have shown to be effective against Sars-Cov-2, while the path of activity is yet to be identified.
\end{abstract}


Identifying an effective drug that can suppress both inflammation and virus proliferation will play a crucial role in the treatment of Covid19 disease. Therefore, we suggest experimental investigation the 28 FDA-approved drugs on DHODH activity and Sars-Cov-2 virus proliferation. Those who are found experimentally effective can play an important role in Covid19 treatment. Moreover, we suggest investigating Covid19 case conditions in patients using schizophrenia and depression drugs.

Keywords: Covid-19, Sars-Cov-2, DHODH, Target Prediction, Molecular Docking 


\section{Introduction}

In December 2019, it was announced that a fatal pneumonia disease occurred in Wuhan, China. Clinicians in China have found that the cause of this disease was a new coronavirus. This virus, called Sars-Cov-2, has been determined as a result of the genome sequencing analysis and was $79.5 \%$ similar genetically to multiple acute respiratory syndrome (SARS) virus ${ }^{1,2}$. This virus, which spread from Wuhan to the whole world, has infected more than 6 million as of May 31, 2020, causing more than 375 thousand deaths. The Sars-Cov-2 virus, which the World Health Organization has declared as a pandemic as of February 11, 2020, causes acute lung injury, as the main cause of death.

More than 80 clinical trials are underway, such as drug development, vaccination studies, and serum/plasma treatment ${ }^{3}$. Considering patient serum amount is low as a recently spreading disease and the vaccine development is expected to take time, it is of great importance to test FDA-approved drugs in the treatment of Covid-19 disease, especially for the rapid control of the disease ${ }^{4}$. Current drug discovery studies focus on RNA polymerase inhibition ${ }^{5}$, ACE-2 and Spike Protein Blockers ${ }^{5-7}$, TMPRSS2 protease inhibitors ${ }^{8}$. These target regions are focused for preventing the virus from binding to the target protein, entry into the cell and replication. However, all these targets under study, to our knowledge, are not particularly focuseed for their effects against acute lung injury, which is the main cause of Covid-19 disease.

As mentioned above, $79.5 \%$ of the genomic sequences of Sars and Sars-Cov-2 viruses are highly similar regions, and their biochemical interactions and pathogenesis have been shown to utilize similar pathways ${ }^{9}$. The binding to the ACE-2 receptor of Sars-Cov-2 lung type-2 endothelial cells, inflammation triggers the cascade, results in respiratory failure due to acute lung respiratory damage (ARDS $)^{9,10}$. One of the most important factors of ARDS formation is due to the uncontrolled release of pro-inflammation cytokines (such as IFN-a, IFN- $\gamma$, IL-1B, IL-6, IL-12, IL-18, TNF- $\alpha$ ). Following virus entry and infection of cells, host immune response and inflammation cascade begin via antigen-presenting cells (APC) and macrophages ${ }^{4,9}$. This process takes place due to two functions of APC: (1) It provides antigen against foreign pathogen to CD4 + T cells (Th1) and (2) releases Interleukin-12 to stimulate Th1 cells. Stimulated Th1 cells stimulate CD8 + T-killer cells (Th2) and attack all cells with a foreign antigen against this pathogen ${ }^{11}$. It also triggers $\mathrm{B}$ cells to produce antigen-specific antibodies 
when Th1 cells are activated. Interferon-1 (IFN-1) has a protective effect especially in SARS and MERS infection. It has been detected in animal studies that IFN-1 signal transduction is suppressed in cells with infection of the SARS virus ${ }^{12}$. Also, antigen creation is suppressed by the virus. It has been determined that non-structural (nsp) proteins located in the ORF regions of the virus genome play a role in these suppression mechanisms ${ }^{13}$.

Most common drug treatment methods aim treatment of the newly infected or about preventing the infection at the first place ${ }^{9}$. However, since patients admit to hospitals with symptoms of cough and fever, at this stage the inflamation has already started. The use of remdesivir and hydroxychloroquine at the time of the outbreak has been comon for the treatment of Covid19. However, with increasing number of clinical studies, it has been revealed that these two drugs do not show statistically significant effect against this disease ${ }^{14}$.

Favalli et al. (2020) stated that similar pathophysiological findings were found between Covid19 disease and Rheumatoid Arthritis diseases ${ }^{15}$. They suggested that anti-rheumatic drugs can also be used in Covid-19 disease ${ }^{15}$. Although rheumatoid arthritis (RA) is painful and quite debilitating, it is a chronic inflammatory disease characterized by gradual destruction of joints, deformity, disability and premature death in infants ${ }^{16}$.

Anti-inflammatory drugs, in particular, anti-cytokines has been used to prevent inflammatory formation ${ }^{17}$. One of these treatment methods has been the suppression of the DHODH (dihydroorotate dehydrogenaze) enzyme ${ }^{18}$. Pyrimidines play roles in the formation of phosphodiester bonds with purines in double helix DNA, glycoprotein, phospholipids, RNA and DNA ${ }^{19,20}$. There are 2 important ways in the synthesis of pyrimidines in most conserved organisms; salvage and de novo pathways ${ }^{19}$. Under normal conditions, along with differentiated cells, inactive lymphocytes prefer salvage pyrimidine synthesis ${ }^{21,24}$. However, upon stimulation, they need de novo pyrimidine synthesis where the DHODH enzyme takes part. With the suppression of pyrimidine synthesis, activated lymphocytes undergo metabolic stress and the release of pro-inflammatory cytokines such as IL-17 and IFN- $\gamma$ decreases leading to apoptosis $^{22-24}$.

Dihydroorotate dehydrogenase (DHODH) is a flavoenzyme localized in the inner membrane of the mitochondria, involved in the 4 th step of de novo pyrimidine synthesis ${ }^{21,25}$. Using Ubiquione as a cofactor, it catalyses dihyrooratate to oratate. It is necessary for the cell as it is the only enzyme that can perform this process during the formation of uridine monophosphate (UMT) used in RNA synthesis ${ }^{20}$. 
DHODH enzyme is proven to play an active role in cancer and immunological disorders such as acute myeloid leukemia, rheumatoid arthritis, multiple sclerosis ${ }^{18,21,26-28}$. In addition, DHODH inhibition has been found to have anti-viral effects against rotavirus, dengue virus, foot and mouth disease virus. ${ }^{29-33}$. Liu et al. (2020) showed that suppression of de novo pyrimidine synthesis in anti-viral treatment strategies, apart from RNA-dependent RNA polymerase inhibition, may be the target mechanism for many viral pathogens including coronavirus ${ }^{34}$.

When the pathogenesis of Covid-19 disease on lung injury was examined, similar immune reactions were detected in autoimmune diseases such as rheumatoid arthiris ${ }^{15}$. Suppression of the DHODH enzyme in humans is a proven treatment method for immune disorders, especially cancer, rheumatoid arthritis (Leflunomide-Arava Company) and multiple sclerosis (Teriflunomide-Aubagio Company).

Beside the anti-inflamatory effect of the DHODH inhibition, the viruses are in need a high amount of nucleic acid to complete their life cycle in the host cell. Therefore, inhibition of nucleotide biosynthesis was previously considered a potential anti-viral strategy ${ }^{6}$. In accordance, DHODH inhibitors used in the treatment of autoimmune diseases have also been identified by studies that have broad spectrum anti-viral effects ${ }^{31}$.

The most detailed research for suppression of Sars-cov-2 virus replication through DHODH inhibition has been published as preprints by Xiong R. et al., (2020) ${ }^{35}$. According to the study announced in Wuhan, inhibition of the DHODH enzyme reported that the Sars-Cov-2 virus reduced the proliferation in the cell, and that it was an important strategy that could be used in Covid-19 disease due to the immune response suppression effect of DHODH inhibitors. The researchers identified 2 candidate molecules with a high binding score that could target the active site of the DHODH enzyme from 280,000 molecules via docking to protein data bank structure of DHODH, 6M2B. Both candidate molecules suppressed Sars-Cov-2 proliferation 17 times stronger $\left(\mathrm{IC}_{50}=17 \mu \mathrm{M}\right)$ compared to FDA approved DHODH inhibitors $\left(\mathrm{IC}_{50}=300\right.$ $\mu \mathrm{M})$. In addition, in the cell culture study, $\mathrm{DHODH}^{+}$and $\mathrm{DHODH}^{-} \mathrm{A} 549$ cells, which was created with the CRISPR technique, were infected with the Sars-Cov-2 virus and the proliferation amount of the viruses was investigated. It was reported that there was no significant change in DHODH-A549 cell proliferation compared to $\mathrm{DHODH}^{+}$cells after 72 hours. In DHODH'A549 cells, the virus was found to grow 1000 times slower. With the CRISPR study, it was determined that DHODH enzyme is important for the virus replication. 
In vitro and clinical studies utilizing DHODH inhibitors has been increasing against Covid19 (Chictr2000030058, ClinicalTrials Code: NCT04361214, ClinicalTrials Code: NCT04379271). Yet, considering the fast pace of the pandemic, and low rate of drugs passing the clinical stage, more candidates are necessary for testing. The aim of our study is to determine potential candidates among approximately 7900 candidate compounds, including FDA approved drugs, to target the DHODH enzyme using molecular docking analysis on 20 different DHODH crystal structure. Those with the high binding energy in all DHODH enzymes tested were distinguished. Among the FDA-approved drugs further in silico target-prediction analysis was performed. The target similarities of the molecules determined by comparing FDAapproved DHODH inhibitor, leflunomide, are discussed. It is important to determine the effects of these drugs with high binding score on the DHODH enzyme obtained in the analysis on the Sars-Cov-2 virus in vitro and in vivo in the global effort to find an effective treatment against Covid-19.

\section{Methods}

\section{Obtaining ligands}

All drug structures of 7900 ligands with a 3D structure are downloaded from DrugBank ${ }^{36}$ and converted from sdf format into individual PDBQT files using an in-house Python code and openbabel (version 3.0.0) ${ }^{37}$. The hydrogens were added /removed in accordance to simulate $\mathrm{pH}$ 7.0 and gasteiger charges were added to PDBQT files. Only the largest and unique fragments were taken in each drug file.

\section{Obtaining receptor files}

From Protein Databank, (www.wwpdb.org) ${ }^{38}$ among all structures of Human DHODH, only the asymetric X-ray crystallography structures with a maximum resolution of $2.0 \AA$ and published after 2010 are selected. Among these structures, some are also eliminated due to reading errors. The following PDB structures were remained: PDB ID's: $2 \mathrm{wv}^{39}, 3 \mathrm{kvj}^{40}, 3 \mathrm{kvl}{ }^{40}$, $4 \mathrm{igh}^{41}, 4 \mathrm{jtu}^{42}, 4 \mathrm{zl1}^{43}, 4 \mathrm{zmg}^{44}, 5 \mathrm{~h} 2 \mathrm{z}^{45}, 5 \mathrm{~h} 73^{46}, 5 \mathrm{hqe}^{47}, 5 \mathrm{k} 9 \mathrm{c}^{27}, 5 \mathrm{k}^{2} \mathrm{~d}^{27}, 5 \mathrm{mut}^{48}, 5 \mathrm{mvc}^{48}, 5 \mathrm{mvd}^{48}$, $6 i d j^{49}, 6 j 3 b^{50}, 6 j 3 c^{50}, 6 j m d^{51}, 6 l z l^{52}$.

\section{Docking analysis}

The remaining 20 PDB files were then aligned to $6 \mathrm{j} 3 \mathrm{c}$ PDB file as a reference using pairwise structure comparison tool on DALI Server ${ }^{53}$. Only the first chain in each file (chain A) was used for the alignment (STable 1). The aligned protein structures were converted to PDBQT files, 
using MGL Tools ${ }^{54}$. All non-polar hydrogens were removed merging charges and polar hydrogens were added where necessary. The charges were recalculated using Kollman charges. All non-standard residues were removed. All water and other molecules except the main chain are removed.

\section{Autodock Vina docking analysis}

Since the all PDB structures were aligned, the active sites also were aligned. A single gridbox with a center at $\mathrm{x}=34.569, \mathrm{y}=-15.848, \mathrm{z}=-18.938 \AA$ ) and sizes of 18,28 and $22 \AA$, at respective edges, encapsulated the active site and was used for all receptors.

Using an in-house Python code and Vina (Autodock), an automated docking was performed for all filtered ligands and receptor files ${ }^{55}$. An exhaustiveness of 16 was used. All Vina docking analysis were performed on a computer with 12 core CPU and 32 GB ECC Ram. Each ligand that received an affinity equal or higher than $-11.0(\mathrm{kcal} / \mathrm{mol})$ for any of the receptors was removed from future docking analysis. All dockings were started using $6 \mathrm{j} 3 \mathrm{c}$ and continued with the rest, in alphabetical order according to PDB IDs.

\section{Autodock 4.2 docking analysis}

Same gridbox used for Vina with a center at $\mathrm{x}=34.569, \mathrm{y}=-15.848, \mathrm{z}=-18.938 \AA$ ) and sizes of 18, 28 and $22 \AA$, at respective edges, was used for docking using Autodock 4. Since Autodock 4.2 requires a step site, the default step size of $0.345 \AA$ was used.

\section{Identifiying interacting aminoacids}

Autodock docking analysis was displayed with MGLtools 1.5.6, and the protein and ligand were recorded in a single pdb file by selecting the best binding affinity from 10 different binding results. Receptor-ligand interactions were analyzed with the DS visualizer program of the obtained pdb.

\section{In silico target predictions}

SMILE codes of the drug candiates were obtained from Pubchem and entered in http://new.swisstargetprediction.ch/ and http://www.pharmaexpert.ru/passonline to search for probable targets in humans based on the similarity to known chemicals in the database ${ }^{56,57}$.

\section{Results and Discussion}


Our study employed around 7900 structures from DrugBank ${ }^{36}$ with $3 \mathrm{~d}$ structures. In our effort to identify possible inhibitor candidates, we have performed molecular docking of these molecules to $20 \mathrm{DHODH}$ crystal structures using a gridbox selected based on the known active site binding inhibitors. A distribution of all binding affinities towards to the first DHODH structures tested (6j3c) was obtained. Of this distribution, structures with affinity better than $11.0 \mathrm{kcal} / \mathrm{mol}$, corresponding to top $12 \%$ percent, was selected for docking on the next DHODH structure (Figure1). Similarly, any structure that failed to achieve at least $11.0 \mathrm{kcal} / \mathrm{mol}$ binding affinity for any of the DHODH structures were filtered out for the rest of the study.

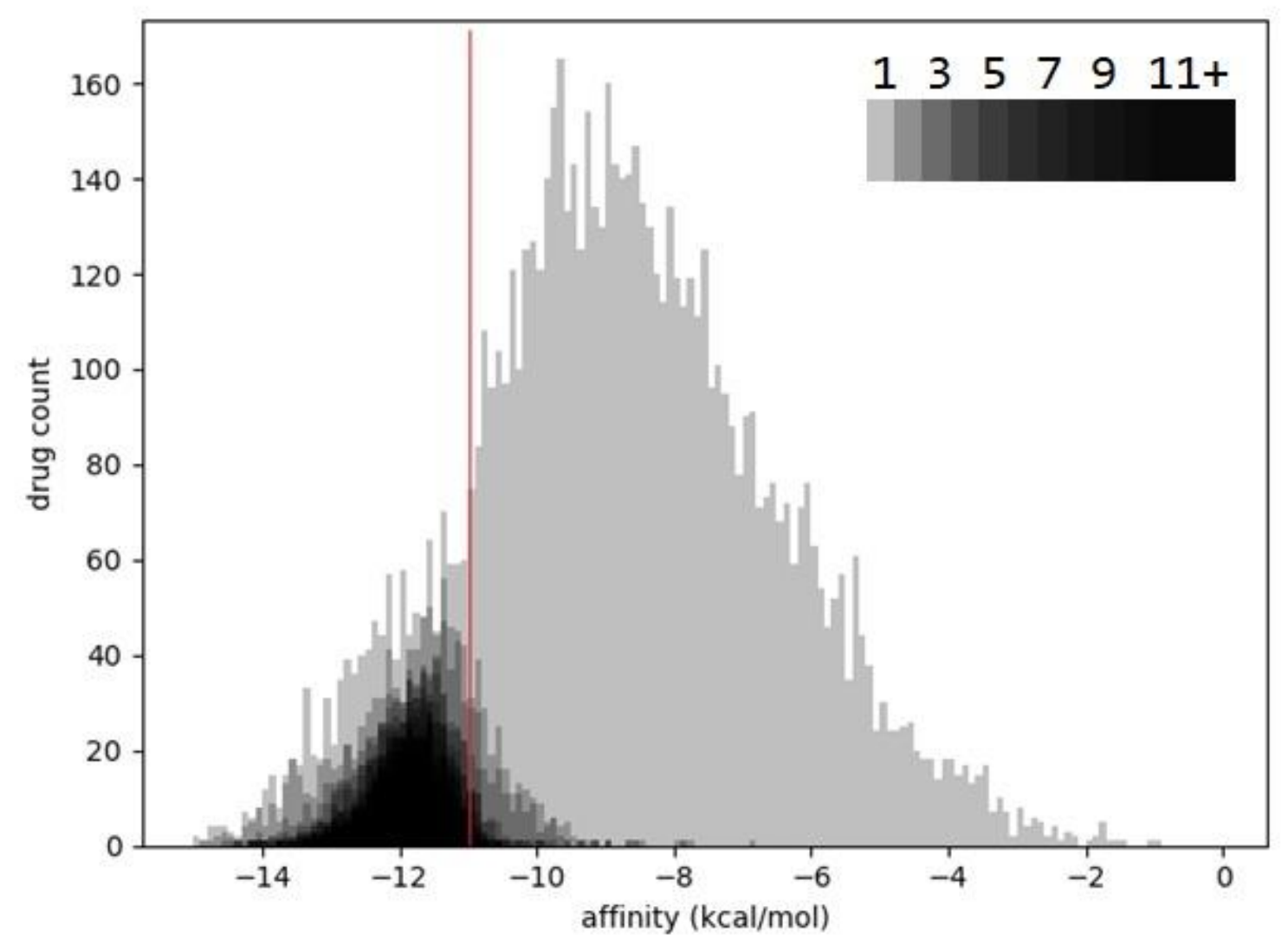

Figure 1. The distributions of drug affinities for each DHODH structure tested. The darker shades indicate the increased number of structures that recoded a drug at corresponding affinity. Red line indicates $-11 \mathrm{kcal} / \mathrm{mol}$, the threshold used to eliminate low affinity drug candidates.

The figure above, indicates the distribution of the drug affinities for all structures tested. The shades indicate the overlapping distributions, as a result, darker shades indicate where the most distributions are accumulated. As can be seen in the figure, the initial distribution obtained with 
$6 \mathrm{j} 3 \mathrm{c}$ was centered around $-9 \mathrm{kcal} / \mathrm{mol}$. After the initial elimination the majority of the drugs were eliminated due to the threshold, and the remaining structures always showed a distribution with a mean of around $-12 \mathrm{kcal} / \mathrm{mol}$ (Table1). A small portion of the drug candidates left over continued to spill above this threshold, resulting of their elimination as well. The continued docking and elimination process decreased the portion of the drugs eliminated in the upcoming analysis.

Table 1. Autodock vina and autodock 4.2 results of FDA approved drugs obtained by extensive molecular docking screening against DHODH structures.

\begin{tabular}{|c|c|c|c|c|c|}
\hline $\begin{array}{l}\text { DrugBank } \\
\text { Code }\end{array}$ & Drug Name & $\begin{array}{l}\text { PDB:6J3C } \\
\text { Autodock Vina } \Delta G \\
\text { (kcal/mol) }\end{array}$ & $\begin{array}{l}\text { PDB:6J3C } \\
\text { Autodock } 4.2 \quad \Delta G \\
(\mathrm{kcal} / \mathrm{mol})\end{array}$ & $\begin{array}{l}\text { Average of } \\
\text { Autodock Vina } \Delta G \\
\text { Results (kcal/mol) }\end{array}$ & $\begin{array}{l}\text { PDB:6J3C Autodock } \\
4.2 \quad \text { Constant of } \\
\text { Inhibition (Ki) }\end{array}$ \\
\hline DB00398 & Sorafenib & -12.7 & -9.3 & -12.365 & $152.27 \mathrm{nM}$ \\
\hline DB00450 & Droperidol & -12 & -7.83 & -11.995 & $1.84 \mu \mathrm{M}$ \\
\hline DB00619 & Imatinib & -11.9 & -9.8 & -12.53 & $65.63 \mathrm{nM}$ \\
\hline DB00734 & Risperidone & -12.7 & -10.16 & -13.25 & $35.64 \mathrm{nM}$ \\
\hline DB01016 & Glyburide & -12.4 & -9.41 & -12.27 & $126.51 \mathrm{nM}$ \\
\hline DB01067 & Glipizide & -11.7 & -9.53 & -12.15 & $102.66 \mathrm{nM}$ \\
\hline DB01184 & Domperidone & -12.2 & -9.22 & -12.155 & $174.27 \mathrm{nM}$ \\
\hline DB01238 & Aripiprazole & -12.1 & -8.81 & -11.745 & $349.33 \mathrm{nM}$ \\
\hline DB01267 & Paliperidone & -12.7 & -9.84 & -13.145 & $61.03 \mathrm{nM}$ \\
\hline DB06144 & Sertindole & -11.6 & -10.65 & -12.17 & $15.71 \mathrm{nM}$ \\
\hline DB06684 & Vilazodone & -12.3 & -10.12 & -12.195 & $38.36 \mathrm{nM}$ \\
\hline DB06817 & Raltegravir & -11.9 & -7.48 & -12.09 & $3.31 \mu \mathrm{M}$ \\
\hline DB08883 & Perampanel & -11.9 & -9.87 & -12.02 & $58.22 \mathrm{nM}$ \\
\hline DB08896 & Regorafenib & -13.1 & -9.17 & -12.675 & $191.04 \mathrm{nM}$ \\
\hline DB08907 & Canagliflozin & -11.9 & -9.75 & -11.79 & $71.00 \mathrm{nM}$ \\
\hline DB08930 & Dolutegravir & -11.8 & -8.9 & -12.11 & $300.44 \mathrm{nM}$ \\
\hline DB09042 & Tedizolid phosphate & -12.1 & -9.38 & -12.18 & $132.42 \mathrm{nM}$ \\
\hline DB09128 & Brexpiprazole & -12.4 & -12.1 & -11.975 & $1.36 \mathrm{nM}$ \\
\hline DB11526 & Masitinib & -12.6 & -7.31 & -13.145 & $4.37 \mu \mathrm{M}$ \\
\hline DB11703 & Acalabrutinib & -12 & -9.94 & -12.15 & $52.01 \mathrm{nM}$ \\
\hline DB11732 & Lasmiditan & -12.4 & -7.2 & -11.885 & $5.31 \mu \mathrm{M}$ \\
\hline DB11791 & Capmatinib & -14.1 & -9.68 & -13.275 & $80.50 \mathrm{nM}$ \\
\hline DB11793 & Niraparib & -11.2 & -8.64 & -11.745 & $462.16 \mathrm{nM}$ \\
\hline DB12836 & Grapiprant & -12.2 & -10.66 & -12.28 & $15.41 \mathrm{nM}$ \\
\hline DB12867 & Benperidol & $\begin{array}{ll}-11.8 \\
\end{array}$ & -8.67 & -11.94 & $439.62 \mathrm{nM}$ \\
\hline DB12978 & Pexidartinib & -12.4 & -8.75 & -12.35 & $388.56 \mathrm{nM}$ \\
\hline DB13931 & Netarsudil & -12.7 & -9.67 & -12.65 & $81.36 \mathrm{nM}$ \\
\hline DB15305 & Risdiplam & -11.8 & -10 & -11.815 & $46.83 \mathrm{nM}$ \\
\hline
\end{tabular}


As a result of the molecular docking using Autodock Vina carried out on 20 different DHODH crystal structures and consequtive elimination of drugs with low affinity, 28 FDA approved and 79 clinically tested candidates were identified (Table 1, Table S2). These drugs are shown to be used effectively in a range of diseases such as rheumatoid arthritis, myeloid leukemia, schizophrenia, depression, HIV infection, spinal muscular atropy and many types of cancer (Table 3). Among the drugs detected, Sorafenib ${ }^{58,59}$, Regorafenib ${ }^{60,61}$, Pexidartinib $^{62,63}$, Capmatinib $^{64,65}$ are used as active drugs in many types of cancer as multiple kinase inhibitors. Raltegravir and Dolutegravir are used as anti-HIV drugs and clinical studies are continuing in covid-19 disease ${ }^{66-68}$. Glyburide, Glipizide and Canagliflozin are used in various type 2 diabetes diseases ${ }^{69-71}$. Droperidol ${ }^{72}$, Risperidone ${ }^{73}$, Domperidone ${ }^{74}$, Aripiprazole $^{75,76}$, Paliperidone $^{77}$, Sertindole ${ }^{78}$, Vilazodone ${ }^{79}$, Brexpiprazole ${ }^{80,81}$, Lasmiditan $^{82}$ are used as serotonin, dopamine receptor antagonist in schizophrenia and depression diseases.

The FDA approved drugs were then docked again to $6 \mathrm{j} 3 \mathrm{c}$ using Autodock 4.2 docking tool. This yielded affinity as well as an inhibition constant (Ki) for all 28 FDA approved drugs (Table1).

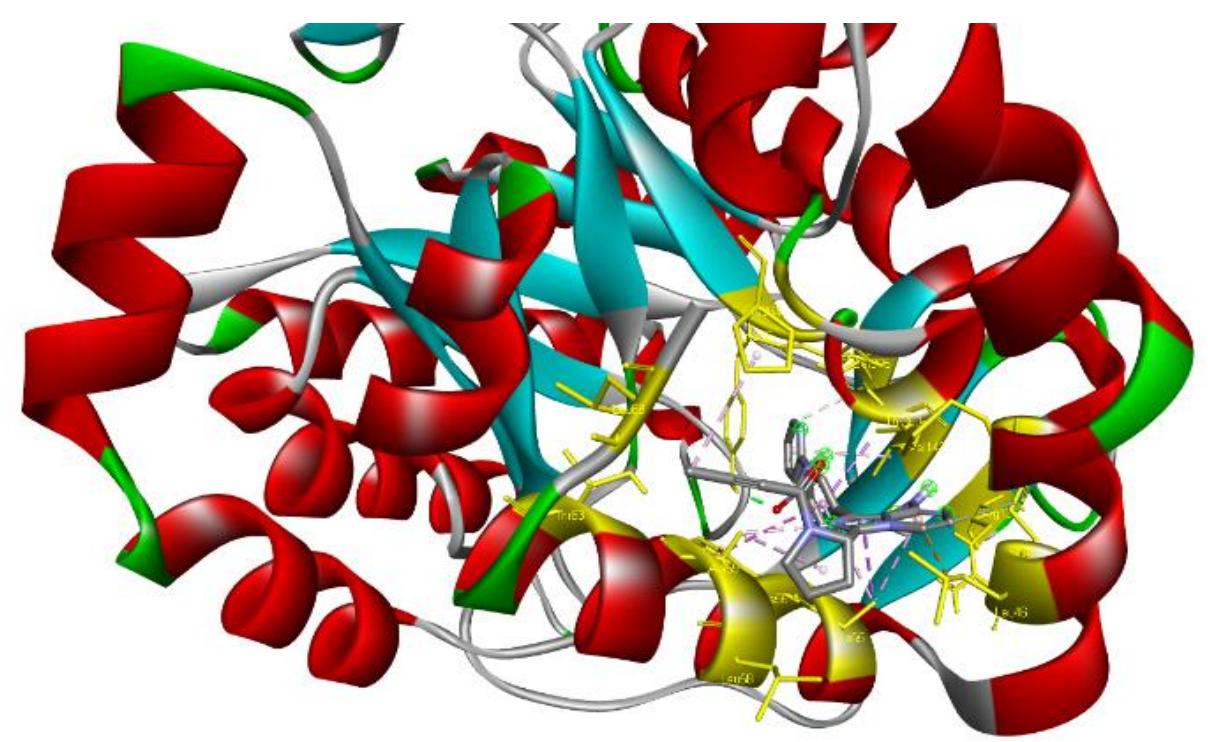

Figure 2. The five amino acids shown in with the highest number of interactions with the selected drugs are indicated with colored atom spheres, HIS56, VAL143, ALA59, ALA55 and TYR356.

The Autodock 4.2 docking results were then analyzed for their interaction with amino acids using DS Visualizer (Table 2) HIS56, VAL143 and ALA59 were the common amino acids that showed interaction with the majority of the drugs (20,19 and 19 drugs, respectively). These were followed by ALA55, TYR356 (17 and 15 drugs, respectively). The amino acids showed 
to be accumulated at the active site cavity, with ability to inhibit the enzyme at this position through competitive inhibition mechanism (Figure 2).

Table 2. The amino acids interacting the drugs detected through analysis of Autodock 4 docking results using DS Visualizer.

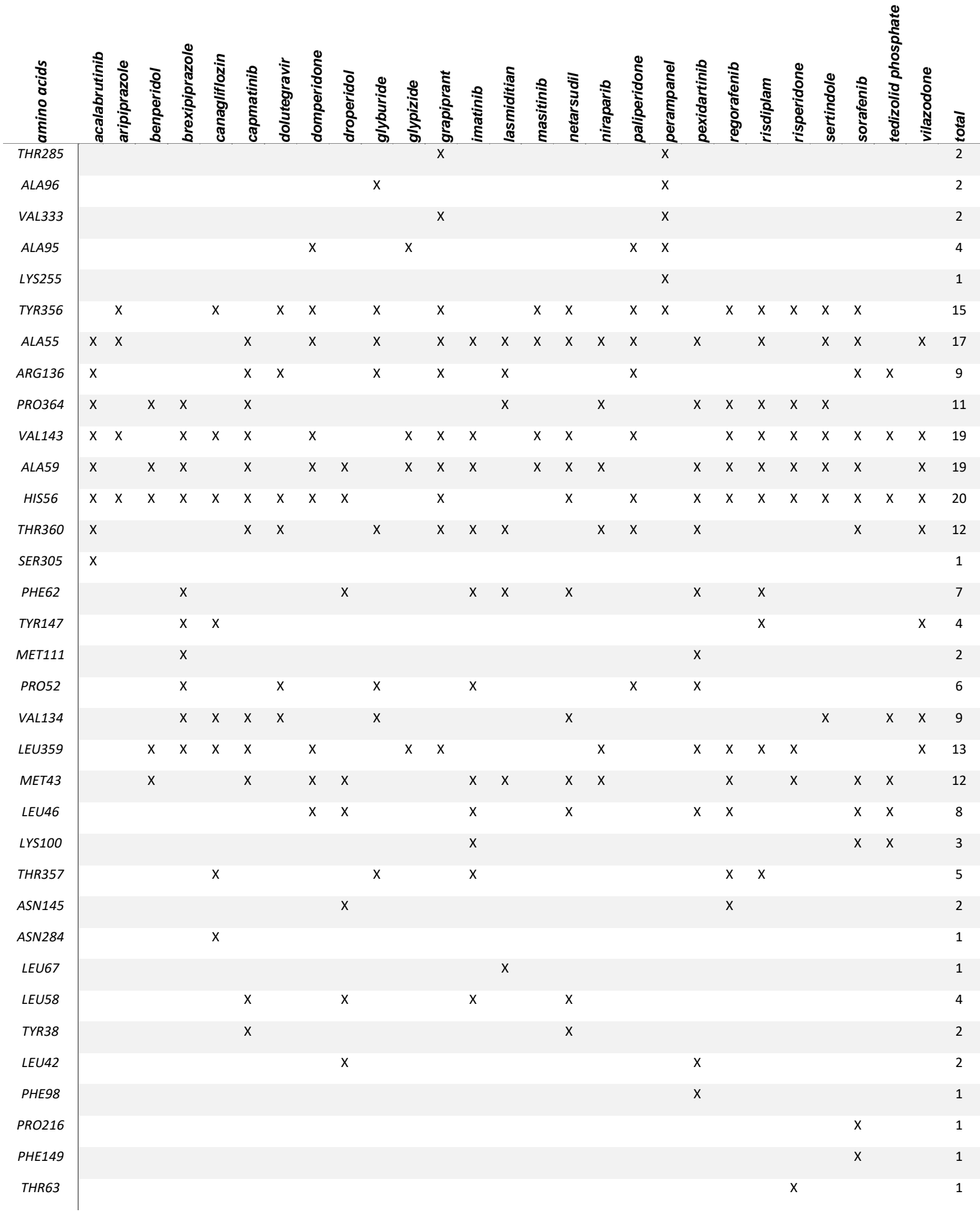


The possible targets were discovered with the SwissTargetPrediction and PASS prediction tools $^{56,57}$. In the SwissTargetPrediction, the interactions of 376,342 compounds with 3068 proteins consist of an experimentally proven data set. The querry molecule is matched according to similiarity among 376,342 compounds and the estimated target proteins are determined. 2D similarity is measured based on Tanitomo index and 3D similarity is measured based on Manhattan distance similarity quantity between Electoroscape 5D flat vector ${ }^{56}$. This tool searches among known ligands based on 2D and 3D similarities to a given querry to predict possible targets. In addition to SwissTargetPrediction the PASS (Prediction of Activity Spectra for Substances) web tool was also used for comparison. PASS web tool calculates using Bayesian approach by considering 2D structural similarities, only. PASS calulates probability for the query to be biologically active (Pa) or inactive $(\mathrm{Pi})$ on target regions. This tool analyzes over 20,000 principal compounds and 180,000 biological related compounds using the MDDR database. In addition, PASS can analyze 3678 pharmacological activity ${ }^{57}$.

Table 3. Drugbank codes, names, targets diseases of the discovered drugs and the diseases they are used in treatment of.

\begin{tabular}{|c|c|c|c|}
\hline $\begin{array}{l}\text { DrugBank } \\
\text { Code }\end{array}$ & Drug Name & Target & Diseases \\
\hline DB00398 & Sorafenib & $\begin{array}{l}\text { multiple intracellular (CRAF, BRAF } \\
\text { and mutant BRAF) and cell surface } \\
\text { kinases (KIT, FLT-3, VEGFR-2, } \\
\text { VEGFR-3, and PDGFR-ß) }\end{array}$ & $\begin{array}{l}\text { Advanced Renal Cell Carcinoma } \\
\text { Gastrointestinal Stromal Tumors } \\
\text { Hemangiosarcoma } \\
\text { Unresectable Hepatocellular Carcinoma } \\
\text { Locally recurrent refractory to radioactive } \\
\text { iodine treatment Thyroid carcinoma } \\
\text { Metastatic refractory to radioactive iodine } \\
\text { treatment Thyroid carcinoma }\end{array}$ \\
\hline DB00450 & Droperidol & $\begin{array}{l}\text { Dopamine( } 2 \text { ) receptor antagonism } \\
\text { with minor antagonistic effects on } \\
\text { alpha-1 adrenergic receptors }\end{array}$ & $\begin{array}{l}\text { Agitation } \\
\text { Chemotherapy-Induced Nausea and } \\
\text { Vomiting (CINV) } \\
\text { Delirium } \\
\text { Nausea and vomiting }\end{array}$ \\
\hline DB00619 & Imatinib & inhibits the Bcr-Abl tyrosine kinase & $\begin{array}{l}\text { treating chronic myelogenous leukemia } \\
\text { (CML), gastrointestinal stromal tumors } \\
\text { (GISTs) and a number of other } \\
\text { malignancies. }\end{array}$ \\
\hline DB00734 & Risperidone & $\begin{array}{l}\text { inhibition of dopaminergic D2 } \\
\text { receptors and serotonergic 5-HT2A } \\
\text { receptors }\end{array}$ & $\begin{array}{l}\text { Acute Mania } \\
\text { Irritability } \\
\text { Mixed manic depressive episode }\end{array}$ \\
\hline
\end{tabular}




\begin{tabular}{|c|c|c|c|}
\hline & & & $\begin{array}{l}\text { Schizophrenia } \\
\text { Agitated psychotic state }\end{array}$ \\
\hline DB01016 & Glyburide & $\begin{array}{l}\text { the closure of ATP-sensitive } \\
\text { potassium channels on beta cells }\end{array}$ & $\begin{array}{l}\text { Gestational Diabetes Mellitus (GDM) } \\
\text { Glycemic Control } \\
\text { Type } 2 \text { Diabetes Mellitus }\end{array}$ \\
\hline DB01067 & Glipizide & $\begin{array}{l}\text { A sulfonylurea medication used in } \\
\text { Type } 2 \text { Diabetes to sensitize pancreatic } \\
\text { beta cells and stimulate insulin release }\end{array}$ & Type 2 Diabetes Mellitus \\
\hline DB01184 & Domperidone & $\begin{array}{l}\text { A specific blocker of dopamine } \\
\text { receptors }\end{array}$ & $\begin{array}{l}\text { Diabetic Gastroparesis } \\
\text { Gastrointestinal Symptoms } \\
\text { Upper gastrointestinal motility disorders }\end{array}$ \\
\hline DB01238 & Aripiprazole & $\begin{array}{l}\text { agonism of dopaminic and 5-HT1A } \\
\text { receptors and antagonism of alpha } \\
\text { adrenergic and 5-HT2A receptors }\end{array}$ & $\begin{array}{l}\text { Agitation } \\
\text { Bipolar 1 Disorder } \\
\text { Irritability } \\
\text { Major Depressive Disorder (MDD) } \\
\text { Mixed manic depressive episode } \\
\text { Psychosis } \\
\text { Psychotic Depression } \\
\text { Schizophrenia } \\
\text { Tourette's Disorder (TD) } \\
\text { Acute Manic episode }\end{array}$ \\
\hline DB01267 & Paliperidone & $\begin{array}{l}\text { central dopamine Type } 2 \text { (D2) and } \\
\text { serotonin Type } 2 \text { (5HT2A) receptor } \\
\text { antagonism. Paliperidone is also active } \\
\text { as an antagonist at alpha } 1 \text { and alpha } 2 \\
\text { adrenergic receptors and H1 } \\
\text { histaminergic receptors }\end{array}$ & $\begin{array}{l}\text { Delusional Parasitosis } \\
\text { Schizoaffective Disorders } \\
\text { Schizophrenia }\end{array}$ \\
\hline DB06144 & Sertindole & $\begin{array}{l}\text { affinity for dopamine D2, serotonin 5- } \\
\text { HT2A and 5-HT2C, and alpha1- } \\
\text { adrenoreceptors }\end{array}$ & Schizophrenia \\
\hline DB06684 & Vilazodone & $\begin{array}{l}\text { high affinity and selectivity for the 5- } \\
\text { hydroxytryptamine (5-HT) transporter } \\
\text { and 5-HT(1A) receptors }\end{array}$ & Major Depressive Disorder (MDD) \\
\hline DB06817 & Raltegravir & $\begin{array}{l}\text { antiretroviral drug produced by Merck } \\
\& \text { Co., used to treat HIV infection }\end{array}$ & $\begin{array}{l}\text { Human Immunodeficiency Virus Type } 1 \\
\text { (HIV-1) Infection }\end{array}$ \\
\hline DB08883 & Perampanel & $\begin{array}{l}\text { a noncompetitive AMPA glutamate } \\
\text { receptor antagonist }\end{array}$ & $\begin{array}{l}\text { Grand mal Generalized tonic-clonic } \\
\text { seizure } \\
\text { Partial-Onset Seizures }\end{array}$ \\
\hline DB08896 & Regorafenib & $\begin{array}{l}\text { an orally-administered inhibitor of } \\
\text { multiple kinases }\end{array}$ & $\begin{array}{l}\text { Metastatic Gastrointestinal Stromal Tumor } \\
\text { Locally advanced Gastrointestinal stromal } \\
\text { tumor } \\
\text { Refractory, metastatic Colorectal cancer } \\
\text { Unresectable Gastrointestinal stromal } \\
\text { tumor }\end{array}$ \\
\hline
\end{tabular}




\begin{tabular}{|c|c|c|c|}
\hline DB08907 & Canagliflozin & $\begin{array}{l}\text { a sodium-glucose cotransporter } 2 \\
\text { (SGLT2) inhibitor }\end{array}$ & $\begin{array}{l}\text { Cardiovascular Events } \\
\text { Cardiovascular Mortality } \\
\text { End Stage Renal Disease (ESRD) } \\
\text { Type } 2 \text { Diabetes Mellitus } \\
\text { Elevated serum creatinine } \\
\text { Hospitalization due to cardiac failure }\end{array}$ \\
\hline DB08930 & Dolutegravir & a HIV-1 intergrase inhibitor & $\begin{array}{l}\text { Human Immunodeficiency Virus Type } 1 \\
\text { (HIV-1) Infection }\end{array}$ \\
\hline DB09042 & Tedizolid phosphate & $\begin{array}{l}\text { generally effective against multidrug- } \\
\text { resistant Gram-positive bacteria }\end{array}$ & $\begin{array}{l}\text { Acute acute bacterial skin and skin } \\
\text { structure infections }\end{array}$ \\
\hline DB09128 & Brexpiprazole & $\begin{array}{l}\text { a novel D2 dopamine and serotonin } \\
\text { 1A partial agonist }\end{array}$ & $\begin{array}{l}\text { Major Depressive Disorder (MDD) } \\
\text { Schizophrenia }\end{array}$ \\
\hline DB11703 & Acalabrutinib & $\begin{array}{l}\text { Bruton Tyrosine Kinase (BTK) } \\
\text { inhibitor }\end{array}$ & $\begin{array}{l}\text { Chronic Lymphocytic Leukaemia (CLL) } \\
\text { Mantle Cell Lymphoma (MCL) } \\
\text { Small Lymphocytic Lymphoma }\end{array}$ \\
\hline DB11732 & Lasmiditan & $\begin{array}{l}\text { selective agonism of the 5- } \\
\text { HT1F receptor }\end{array}$ & $\begin{array}{l}\text { Migraine Headache, With or Without } \\
\text { Aura }\end{array}$ \\
\hline DB11791 & Capmatinib & a small molecule kinase inhibitor & Metastatic Non-Small Cell Lung Cancer \\
\hline DB11793 & Niraparib & orally active PARP inhibitor & $\begin{array}{l}\text { Fallopian Tube Cancer } \\
\text { Ovarian Epithelial Cancer } \\
\text { Primary Peritoneal Cancer }\end{array}$ \\
\hline DB12836 & Grapiprant & prostaglandin receptor antagonists & $\begin{array}{l}\text { The effects of grapiprant have been } \\
\text { reported to be effective in the relief from } \\
\text { arthritic pain in canine patients }\end{array}$ \\
\hline DB12867 & Benperidol & mechanism not clearly known & $\begin{array}{l}\text { Dementia, Depression, Schizophrenia, } \\
\text { Anxiety Disorders, and Psychosomatic } \\
\text { Disorders, among others. }\end{array}$ \\
\hline DB12978 & Pexidartinib & $\begin{array}{l}\text { a selective tyrosine kinase } \\
\text { inhibitor (CSF1) }\end{array}$ & $\begin{array}{l}\text { Symptomatic Tenosynovial Giant Cell } \\
\text { Tumor }\end{array}$ \\
\hline DB13931 & Netarsudil & A Rho kinase inhibitor & Increased intraocular pressure \\
\hline DB15305 & Risdiplam & $\begin{array}{l}\text { orally bioavailable mRNA splicing } \\
\text { modifier }\end{array}$ & Spinal muscular atrophy (SMA) \\
\hline
\end{tabular}

In silico target prediction analysis of potential DHODH inhibitor candidates determined by comparing to FDA approved DHODH inhibitor, Leflunomide. Leflunomide is shown as probable inhibitor to other oxidoreductates, xanthine dehydrogenase, monoamine oxidase $\mathrm{B}$, 
arachidonate-5-lipogenase, cylclooxygenase-2 according to SwissTargetPrediction. Similarly, a number of drug candidates were also shown as probable inhibitors to the same oxidoreductases (Table 4). While only only acalabrutinib and raltegravir was found directly associated to DHODH, Aripiprazole, Benperidol, Brexpiprazole, Canagliflozin, Capmatinib, Domperidone, Droperidol, Grapiprant, Lasmiditan, Perampanel, Raltegravir, Risdiplam, Sertindole and Thedizolid phosphate have been found to be putative targets for other various oxidoreductases.

When compared using PASS, 4 out of 28 number of drugs were found directly associated to Dihydroorotase inhibition, as well as Leflunomide, suggesting a sound the experimental design. Capmatinib, Netarsudil, Regorafenib and Sorafenib are determined as Dihydroorotase inhibitor by PASS, contradicting SwissTargetPrediction results. However, an antiinflamatory activity was associated to a larger set including Dolutegravir, Lasmiditan, Mastinib, Netarsudil, Paliperidone, Perampanel, Pexidartinib, Risdiplam and Risperidone, most of which were not associated to DHODH inhibition directly (Table S3).

Table 4. Among the 28 drugs detected in our list, those with similarity to various oxidoreductase inhibitors are listed. The data were obtained from the SwissTargetPrediction tool. The score (Probability) between 0-1 was converted as a percentage. DHODH inhibitor, Leflunomide, is listed as reference.

\begin{tabular}{|c|c|c|c|c|c|c|}
\hline Drug Name & Target & Common name & ChEMBL ID & Target Class & $\begin{array}{l}\text { Probability } \\
(\%)\end{array}$ & $\begin{array}{l}\text { Known } \\
\text { actives } \\
(3 \mathrm{D} / 2 \mathrm{D})\end{array}$ \\
\hline \multirow[t]{5}{*}{ Leflunomide } & $\begin{array}{l}\text { Dihydroorotate } \\
\text { dehydrogenase } \\
\text { (by } \\
\text { homology) }\end{array}$ & DHODH & CHEMBL1966 & Oxidoreductase & 100 & $12 / 4$ \\
\hline & $\begin{array}{l}\text { Xanthine } \\
\text { dehydrogenase }\end{array}$ & $\mathrm{XDH}$ & CHEMBL1929 & Oxidoreductase & 11.2 & $4 / 0$ \\
\hline & $\begin{array}{l}\text { Monoamine } \\
\text { oxidase B }\end{array}$ & MAOB & CHEMBL2039 & Oxidoreductase & 11.2 & $40 / 0$ \\
\hline & $\begin{array}{l}\text { Arachidonate 5- } \\
\text { lipoxygenase }\end{array}$ & ALOX5 & CHEMBL215 & Oxidoreductase & 11.2 & $6 / 0$ \\
\hline & $\begin{array}{l}\text { Cyclooxygenase- } \\
2\end{array}$ & PTGS2 & CHEMBL230 & Oxidoreductase & 11.2 & $78 / 0$ \\
\hline \multirow[t]{3}{*}{ Acalabrutinib } & $\begin{array}{l}\text { Dihydroorotate } \\
\text { dehydrogenase } \\
\text { (by } \\
\text { homology) }\end{array}$ & DHODH & CHEMBL1966 & Oxidoreductase & 11 & $18 / 0$ \\
\hline & $\begin{array}{l}\text { Cyclooxygenase- } \\
2\end{array}$ & PTGS2 & CHEMBL230 & Oxidoreductase & 11 & $343 / 0$ \\
\hline & $\begin{array}{l}\text { Inosine-5'- } \\
\text { monophosphate } \\
\text { dehydrogenase } 2\end{array}$ & IMPDH2 & CHEMBL2002 & Oxidoreductase & 11 & $89 / 0$ \\
\hline
\end{tabular}




\begin{tabular}{|c|c|c|c|c|c|c|}
\hline & $\begin{array}{l}\text { Monoamine } \\
\text { oxidase B }\end{array}$ & MAOB & CHEMBL2039 & Oxidoreductase & 11 & $319 / 0$ \\
\hline \multirow[t]{3}{*}{ Aripiprazole } & $\begin{array}{l}\text { Monoamine } \\
\text { oxidase B }\end{array}$ & MAOB & CHEMBL2039 & Oxidoreductase & 10.6 & $62 / 15$ \\
\hline & $\begin{array}{ll}\text { Egl nine } \\
\text { homolog } 1\end{array}$ & EGLN1 & CHEMBL5697 & Oxidoreductase & 10.6 & $20 / 0$ \\
\hline & $\begin{array}{l}\text { Arachidonate 5- } \\
\text { lipoxygenase }\end{array}$ & ALOX5 & CHEMBL215 & Oxidoreductase & 10.6 & $53 / 0$ \\
\hline Benperidol & $\begin{array}{ll}\text { Egl } & \text { nine } \\
\text { homolog } 1 & \end{array}$ & EGLN1 & CHEMBL5697 & Oxidoreductase & 11.5 & $51 / 0$ \\
\hline Brexpiprazole & $\begin{array}{l}\text { Arachidonate 5- } \\
\text { lipoxygenase }\end{array}$ & ALOX5 & CHEMBL215 & Oxidoreductase & 11.8 & $80 / 0$ \\
\hline \multirow[t]{2}{*}{ Canagliflozin } & $\begin{array}{l}\text { Glyceraldehyde- } \\
\text { 3- } \\
\text { phosphate } \\
\text { dehydrogenase } \\
\text { liver }\end{array}$ & GAPDH & CHEMBL2284 & Oxidoreductase & 11.8 & $10 / 0$ \\
\hline & $\begin{array}{l}\text { Inosine-5'- } \\
\text { monophosphate } \\
\text { dehydrogenase } 2\end{array}$ & IMPDH2 & CHEMBL2002 & Oxidoreductase & 11.8 & $34 / 0$ \\
\hline \multirow[t]{2}{*}{ Capmatinib } & $\begin{array}{l}\text { Monoamine } \\
\text { oxidase B }\end{array}$ & MAOB & CHEMBL2039 & Oxidoreductase & 11.8 & $278 / 0$ \\
\hline & $\begin{array}{l}\text { Inosine-5'- } \\
\text { monophosphate } \\
\text { dehydrogenase } 2\end{array}$ & IMPDH2 & CHEMBL2002 & Oxidoreductase & 11.8 & $173 / 0$ \\
\hline \multirow[t]{2}{*}{ Domperidone } & $\begin{array}{l}\text { Inosine-5'- } \\
\text { monophosphate } \\
\text { dehydrogenase } 2\end{array}$ & IMPDH2 & CHEMBL2002 & Oxidoreductase & 10.6 & $99 / 0$ \\
\hline & $\begin{array}{l}\text { Cyclooxygenase- } \\
2\end{array}$ & PTGS2 & CHEMBL230 & Oxidoreductase & 10.6 & $502 / 0$ \\
\hline Droperidol & $\begin{array}{l}\text { Inosine-5'- } \\
\text { monophosphate } \\
\text { dehydrogenase } 2\end{array}$ & IMPDH2 & CHEMBL2002 & Oxidoreductase & 11.5 & $155 / 0$ \\
\hline \multirow[t]{2}{*}{ Grapiprant } & $\begin{array}{l}\text { HMG-CoA } \\
\text { reductase (by } \\
\text { homology) }\end{array}$ & HMGCR & CHEMBL402 & Oxidoreductase & 11 & $161 / 0$ \\
\hline & $\begin{array}{l}\text { Arachidonate 5- } \\
\text { lipoxygenase }\end{array}$ & ALOX5 & CHEMBL215 & Oxidoreductase & 11 & $167 / 0$ \\
\hline Lasmiditan & $\begin{array}{l}\text { Cyclooxygenase- } \\
2\end{array}$ & PTGS2 & CHEMBL230 & Oxidoreductase & 11.3 & $18 / 0$ \\
\hline \multirow[t]{2}{*}{ Perampanel } & $\begin{array}{l}\text { Monoamine } \\
\text { oxidase B }\end{array}$ & MAOB & CHEMBL2039 & Oxidoreductase & 11.3 & $116 / 0$ \\
\hline & $\begin{array}{l}\text { Dihydrofolate } \\
\text { reductase }\end{array}$ & DHFR & CHEMBL202 & Oxidoreductase & 11.3 & $9 / 0$ \\
\hline Raltegravir & $\begin{array}{ll}\text { Egl } & \text { nine } \\
\text { homolog } 1 & \end{array}$ & EGLN1 & CHEMBL5697 & Oxidoreductase & 10.6 & $67 / 0$ \\
\hline
\end{tabular}




\begin{tabular}{|c|c|c|c|c|c|c|}
\hline & $\begin{array}{l}\text { 4-hydroxyphenyl } \\
\text { pyruvate } \\
\text { dioxygenase }\end{array}$ & HPD & CHEMBL1861 & Oxidoreductase & 10.6 & $74 / 0$ \\
\hline & $\begin{array}{l}\text { Dihydroorotate } \\
\text { dehydrogenase } \\
\text { (by } \\
\text { homology) }\end{array}$ & DHODH & CHEMBL1966 & Oxidoreductase & 0 & $12 / 0$ \\
\hline & $\begin{array}{l}\text { Monoamine } \\
\text { oxidase A }\end{array}$ & MAOA & CHEMBL1951 & Oxidoreductase & 0 & $1 / 0$ \\
\hline & $\begin{array}{l}\text { Cyclooxygenase- } \\
2\end{array}$ & PTGS2 & CHEMBL230 & Oxidoreductase & 0 & $1 / 0$ \\
\hline Risdiplam & $\begin{array}{l}\text { Monoamine } \\
\text { oxidase B }\end{array}$ & MAOB & CHEMBL2039 & Oxidoreductase & 10.6 & $9 / 0$ \\
\hline \multirow[t]{2}{*}{ Sertindole } & $\begin{array}{l}\text { Monoamine } \\
\text { oxidase A }\end{array}$ & MAOA & CHEMBL1951 & Oxidoreductase & 11.8 & $56 / 0$ \\
\hline & $\begin{array}{l}\text { Monoamine } \\
\text { oxidase B }\end{array}$ & MAOB & CHEMBL2039 & Oxidoreductase & 11.8 & $70 / 0$ \\
\hline \multirow[t]{2}{*}{$\begin{array}{l}\text { Thedizolid } \\
\text { phosphate }\end{array}$} & $\begin{array}{l}\text { Monoamine } \\
\text { oxidase A }\end{array}$ & MAOA & CHEMBL1951 & Oxidoreductase & 15 & $0 / 11$ \\
\hline & $\begin{array}{l}\text { Monoamine } \\
\text { oxidase B }\end{array}$ & MAOB & CHEMBL2039 & Oxidoreductase & 15 & $0 / 1$ \\
\hline
\end{tabular}

It is worth to note that, just like in Lenfunomide, most of these drug candidates were found as probable targets for not only oxidoreductases but also dopamine-serotonine receptors, attracting our attention.

As mentioned previously, 8 of the candidates, were found to be used as dopamin-serotonin receptor antagonists using SwissTargetPrediction. Oddly, in agreement with it, Leflunomide, as the known DHODH inhibitor but not being listed in our drug candidates, also showed high similarity to dopamine and norepinephrine transporter antagonists as well as the DHODH effectors. In addition, antagonists of other serotonin-receptors, 5HT-6, 5HT-2a, 5HT-2b, 5HT2c, also show a degree of similarity with Leflunomide (Table 5).

The serotonin function is regulated by 7 members (15 subtypes) of the serotonin receptor in mammals ${ }^{83}$. Immune cells express 5HT-1,5HT-2,5HT-3,5HT-4 and 5HT-7 class serotonin receptor, serotonin transporter (SERT), important enzyme for serotonin synthesis (TPH) and monoamine oxidase (MAO) for serotonin degredation ${ }^{84}$.

Remarkably, among our candidates, Aripirazole, Domperidone, Lasmiditan, and Sertindole showed to be broad serotonin receptor antigonists as well as oxidoreductase inhibitors. Sertindole and Aripiprazole also have structural similarity with monoamine oxidase enzyme inhibitors. The fact that 5-hydroxytrypamine (5-HT) antagonists are also shown as probable 
inhibitor for monoamine oxidase, which plays a role in serotonin degredation, and show high binding affinity to DHODH according to molecular docking analysis raises the question whether DHODH plays a role in the anti-inflammatory effect of 5-HT antagonists. In structural similarity analyzes, similar targets were found between leflunomide and 5-HT antagonist drugs, and 5-HT antagonist drugs were among the molecules with the highest binding affinity to the DHODH enzyme among the 7900 molecules. It has been demonstrated by other studies that 5HT antigonists cause suppression of cytokine release in immune cells by causing serotonin blocking ${ }^{83,85-89}$. However these studies did not consider or tested for DHODH inhibition that may be on the main pathway to the anti-inflammatory affect.

The aformentioned SwissTargetPrediction results also supported by the PASS analysis. Accordinly, besides our reference molecule, Lenfunomide, Acalabrutinib, Aripiprazole, Benperidol, Brexipipirazole, Domperidone, Droperidol, Glipizide, Glyburide, Imatinib, Lasmiditan, Masitinib, Netarsudil, Nirapanib, Paliperidone, Risperidone, Sertindole and Vilazodone are predicted as antagonists for various members of 5-HTs. 10 of these drugs were also associated to mood disorder treatment.

Briefly, an apparent similarity between serotonine-dopamine receptor inhibitors and DHODH inhibitors was supported by both in silico analysis tools we have utilized. Despite, the anti-inflammatory effects of 5-HT antagonist drugs used in diseases such as schizophrenia and depression have not been fully elucidated. For this reason, it should be taken into consideration that possible DHODH inhibitory activities of the specified molecules may be responsible for the observed antiinflamatory effect.

Table 5. List of discovered drugs showing similarity to serotonin-dopamine receptor antagonists. The data were obtained from the SwissTargetPrediction tool. The score (Probability) between 0-1 was converted as a percentage. DHODH inhibitor, Leflunomide, is listed as reference.

\begin{tabular}{|l|l|l|l|l|l|l|}
\hline \multirow{2}{*}{ Drug Name } & Target & Common name & ChEMBL ID & Target Class & $\begin{array}{l}\text { Probability } \\
\mathbf{( \% )}\end{array}$ & $\begin{array}{l}\text { Known } \\
\text { actives } \\
\mathbf{( 3 D / 2 D})\end{array}$ \\
\hline Leflunomide & $\begin{array}{l}\text { Norepinephrine } \\
\text { transporter }\end{array}$ & SLC6A2 & CHEMBL222 & $\begin{array}{l}\text { Electrochemical } \\
\text { transporter }\end{array}$ & 100 & $20 / 1$ \\
\hline & $\begin{array}{l}\text { Dopamine } \\
\text { transporter }\end{array}$ & SLC6A3 & CHEMBL238 & $\begin{array}{l}\text { Electrochemical } \\
\text { transporter }\end{array}$ & 100 & $15 / 1$ \\
\cline { 2 - 7 } & $\begin{array}{l}\text { Serotonin 6 } \\
\text { HT6) } \\
\text { receptor }\end{array}$ & HTR6 & CHEMBL3371 & $\begin{array}{l}\text { Family A G } \\
\text { proteincoupled } \\
\text { receptor }\end{array}$ & 11.2 & $13 / 0$ \\
\cline { 2 - 7 } & $\begin{array}{l}\text { Androgen } \\
\text { Receptor }\end{array}$ & AR & CHEMBL1871 & Nuclear receptor & 11.2 & $176 / 0$ \\
\cline { 2 - 7 }
\end{tabular}




\begin{tabular}{|c|c|c|c|c|c|c|}
\hline \multirow[b]{5}{*}{ Aripiprazole } & $\begin{array}{l}\text { Serotonin 2a (5- } \\
\text { HT2a) receptor }\end{array}$ & HTR2A & CHEMBL224 & $\begin{array}{l}\text { Family A G } \\
\text { proteincoupled } \\
\text { receptor }\end{array}$ & 11.2 & $33 / 0$ \\
\hline & $\begin{array}{l}\text { Serotonin 2c (5- } \\
\text { HT2c) receptor }\end{array}$ & HTR2C & CHEMBL225 & $\begin{array}{l}\text { Family A G } \\
\text { proteincoupled } \\
\text { receptor }\end{array}$ & 11.2 & $35 / 0$ \\
\hline & $\begin{array}{l}\text { Serotonin } 2 b \text { (5- } \\
\text { HT2b) receptor }\end{array}$ & HTR2B & CHEMBL1833 & $\begin{array}{l}\text { Family A G } \\
\text { proteincoupled } \\
\text { receptor }\end{array}$ & 0 & $16 / 0$ \\
\hline & $\begin{array}{l}\text { Dopamine D2 } \\
\text { receptor }\end{array}$ & DRD2 & CHEMBL217 & $\begin{array}{l}\text { Family A G } \\
\text { proteincoupled } \\
\text { receptor }\end{array}$ & 0 & $1 / 0$ \\
\hline & $\begin{array}{l}\text { Serotonin } 2 b(5- \\
\text { HT2b) receptor }\end{array}$ & HTR2B & CHEMBL1833 & $\begin{array}{l}\text { Family A G } \\
\text { proteincoupled } \\
\text { receptor }\end{array}$ & 100 & $175 / 29$ \\
\hline & $\begin{array}{l}\text { Serotonin } 1 b \text { (5- } \\
\text { HT1b) receptor }\end{array}$ & HTR1B & CHEMBL1898 & $\begin{array}{l}\text { Family A G } \\
\text { proteincoupled } \\
\text { receptor }\end{array}$ & 100 & $492 / 35$ \\
\hline & $\begin{array}{l}\text { Serotonin 3a (5- } \\
\text { HT3a) receptor }\end{array}$ & HTR3A & CHEMBL1899 & $\begin{array}{l}\text { Family A G } \\
\text { proteincoupled } \\
\text { receptor }\end{array}$ & 100 & $74 / 1$ \\
\hline & $\begin{array}{l}\text { Serotonin 1d (5- } \\
\text { HT1d) receptor }\end{array}$ & HTR1D & CHEMBL1983 & $\begin{array}{l}\text { Family A G } \\
\text { proteincoupled } \\
\text { receptor }\end{array}$ & 100 & $471 / 14$ \\
\hline & $\begin{array}{l}\text { Serotonin 1a (5- } \\
\text { HT1a) receptor }\end{array}$ & HTR1A & CHEMBL214 & $\begin{array}{l}\text { Family A G } \\
\text { proteincoupled } \\
\text { receptor }\end{array}$ & 100 & $1215 / 127$ \\
\hline & $\begin{array}{l}\text { Serotonin 2a (5- } \\
\text { HT2a) receptor }\end{array}$ & HTR2A & CHEMBL224 & $\begin{array}{l}\text { Family A G } \\
\text { proteincoupled } \\
\text { receptor }\end{array}$ & 100 & $1507 / 160$ \\
\hline & $\begin{array}{l}\text { Dopamine D1 } \\
\text { receptor }\end{array}$ & DRD1 & CHEMBL2056 & $\begin{array}{l}\text { Family A G } \\
\text { proteincoupled } \\
\text { receptor }\end{array}$ & 100 & $196 / 18$ \\
\hline & $\begin{array}{l}\text { Dopamine D2 } \\
\text { receptor }\end{array}$ & DRD2 & CHEMBL217 & $\begin{array}{l}\text { Family A G } \\
\text { proteincoupled } \\
\text { receptor }\end{array}$ & 100 & $3320 / 423$ \\
\hline & $\begin{array}{l}\text { Dopamine D3 } \\
\text { receptor }\end{array}$ & DRD3 & CHEMBL234 & $\begin{array}{l}\text { Family A G } \\
\text { proteincoupled } \\
\text { receptor }\end{array}$ & 100 & $1610 / 162$ \\
\hline & $\begin{array}{l}\text { Dopamine D4 } \\
\text { receptor }\end{array}$ & DRD4 & CHEMBL219 & $\begin{array}{l}\text { Family A G } \\
\text { proteincoupled } \\
\text { receptor }\end{array}$ & 100 & $647 / 181$ \\
\hline & $\begin{array}{l}\text { Serotonin 2c (5- } \\
\text { HT2c) receptor }\end{array}$ & HTR2C & CHEMBL225 & $\begin{array}{l}\text { Family A G } \\
\text { proteincoupled } \\
\text { receptor }\end{array}$ & 100 & $484 / 47$ \\
\hline & $\begin{array}{l}\text { Serotonin } \\
\text { transporter }\end{array}$ & SLC6A4 & CHEMBL228 & $\begin{array}{l}\text { Electrochemical } \\
\text { transporter }\end{array}$ & 100 & $1188 / 102$ \\
\hline
\end{tabular}




\begin{tabular}{|c|c|c|c|c|c|c|}
\hline & HERG & KCNH2 & CHEMBL240 & $\begin{array}{l}\text { Voltage-gated } \\
\text { ion } \\
\text { channel }\end{array}$ & 100 & $1035 / 39$ \\
\hline & $\begin{array}{l}\text { Serotonin } 6 \\
\text { HT6) receptor }\end{array}$ & HTR6 & CHEMBL3371 & $\begin{array}{l}\text { Family A G } \\
\text { proteincoupled } \\
\text { receptor }\end{array}$ & 100 & $371 / 43$ \\
\hline & $\begin{array}{l}\text { Serotonin } 7 \text { (5- } \\
\text { HT7) receptor }\end{array}$ & HTR7 & CHEMBL3155 & $\begin{array}{l}\text { Family A G } \\
\text { proteincoupled } \\
\text { receptor }\end{array}$ & 100 & $602 / 55$ \\
\hline & $\begin{array}{l}\text { Serotonin 5a (5- } \\
\text { H5a) receptor }\end{array}$ & HTR5a & CHEMBL3426 & $\begin{array}{l}\text { Family A G } \\
\text { proteincoupled } \\
\text { receptor }\end{array}$ & 100 & $34 / 1$ \\
\hline & $\begin{array}{l}\text { Prostanoid EP2 } \\
\text { receptor }\end{array}$ & PTGER2 & CHEMBL1881 & $\begin{array}{l}\text { Family A G } \\
\text { proteincoupled } \\
\text { receptor }\end{array}$ & 10.6 & $9 / 0$ \\
\hline \multirow[t]{11}{*}{ Domperidone } & $\begin{array}{l}\text { Serotonin } 2 b(5- \\
\text { HT2b) receptor }\end{array}$ & HTR2B & CHEMBL1833 & $\begin{array}{l}\text { Family A G } \\
\text { proteincoupled } \\
\text { receptor }\end{array}$ & 100 & $60 / 4$ \\
\hline & $\begin{array}{l}\text { Serotonin 1a (5- } \\
\text { HT1a) receptor }\end{array}$ & HTR1A & CHEMBL214 & $\begin{array}{l}\text { Family A G } \\
\text { proteincoupled } \\
\text { receptor }\end{array}$ & 58.9 & $277 / 20$ \\
\hline & $\begin{array}{l}\text { Serotonin 2a (5- } \\
\text { HT2a) receptor }\end{array}$ & HTR2A & CHEMBL224 & $\begin{array}{l}\text { Family A G } \\
\text { proteincoupled } \\
\text { receptor }\end{array}$ & 100 & $413 / 35$ \\
\hline & $\begin{array}{l}\text { Serotonin } 6 \text { (5- } \\
\text { HT6) receptor }\end{array}$ & HTR6 & CHEMBL3371 & $\begin{array}{l}\text { Family A G } \\
\text { proteincoupled } \\
\text { receptor }\end{array}$ & 10.6 & $204 / 13$ \\
\hline & $\begin{array}{l}\text { Serotonin } 7 \\
\text { HT7) receptor }\end{array}$ & HTR7 & CHEMBL3155 & $\begin{array}{l}\text { Family A G } \\
\text { proteincoupled } \\
\text { receptor }\end{array}$ & 10.6 & $128 / 45$ \\
\hline & $\begin{array}{l}\text { Serotonin 2c (5- } \\
\text { HT2c) receptor }\end{array}$ & HTR2C & CHEMBL225 & $\begin{array}{l}\text { Family A G } \\
\text { proteincoupled } \\
\text { receptor }\end{array}$ & 100 & $291 / 6$ \\
\hline & $\begin{array}{l}\text { Dopamine D2 } \\
\text { receptor }\end{array}$ & DRD2 & CHEMBL217 & $\begin{array}{l}\text { Family A G } \\
\text { proteincoupled } \\
\text { receptor }\end{array}$ & 100 & $529 / 73$ \\
\hline & $\begin{array}{l}\text { Dopamine D3 } \\
\text { receptor }\end{array}$ & DRD3 & CHEMBL234 & $\begin{array}{l}\text { Family A G } \\
\text { proteincoupled } \\
\text { receptor }\end{array}$ & 100 & $245 / 28$ \\
\hline & $\begin{array}{l}\text { Dopamine D4 } \\
\text { receptor }\end{array}$ & DRD4 & CHEMBL219 & $\begin{array}{l}\text { Family A G } \\
\text { proteincoupled } \\
\text { receptor }\end{array}$ & 10.6 & $280 / 16$ \\
\hline & $\begin{array}{l}\text { Serotonin } \\
\text { transporter }\end{array}$ & SLC6A4 & CHEMBL228 & $\begin{array}{l}\text { Electrochemical } \\
\text { transporter }\end{array}$ & 100 & $128 / 25$ \\
\hline & HERG & KCNH2 & CHEMBL240 & $\begin{array}{l}\text { Voltage-gated } \\
\text { ion } \\
\text { channel }\end{array}$ & 100 & $378 / 69$ \\
\hline
\end{tabular}




\begin{tabular}{|c|c|c|c|c|c|c|}
\hline \multirow[b]{2}{*}{ Lasmiditan } & $\begin{array}{l}\text { Norepinephrine } \\
\text { transporter }\end{array}$ & SLC6A2 & CHEMBL222 & $\begin{array}{l}\text { Electrochemical } \\
\text { transporter }\end{array}$ & 100 & $10 / 31$ \\
\hline & $\begin{array}{l}\text { Serotonin 1f (5- } \\
\text { HT1f) } \\
\text { receptor }\end{array}$ & HTR1F & CHEMBL1805 & $\begin{array}{l}\text { Family A G } \\
\text { proteincoupled } \\
\text { receptor }\end{array}$ & 67.3 & $93 / 50$ \\
\hline \multirow[t]{13}{*}{ Sertindole } & $\begin{array}{l}\text { Serotonin } 1 \mathrm{~b}(5- \\
\text { HT1b) receptor }\end{array}$ & HTR1B & CHEMBL1898 & $\begin{array}{l}\text { Family A G } \\
\text { proteincoupled } \\
\text { receptor }\end{array}$ & 100 & $535 / 241$ \\
\hline & $\begin{array}{l}\text { Serotonin 1d (5- } \\
\text { HT1d) receptor }\end{array}$ & HTR1D & CHEMBL1983 & $\begin{array}{l}\text { Family A G } \\
\text { proteincoupled } \\
\text { receptor }\end{array}$ & 11.8 & $488 / 218$ \\
\hline & $\begin{array}{l}\text { Serotonin 1a (5- } \\
\text { HT1a) receptor }\end{array}$ & HTR1A & CHEMBL214 & $\begin{array}{l}\text { Family A G } \\
\text { proteincoupled } \\
\text { receptor }\end{array}$ & 100 & $1452 / 128$ \\
\hline & $\begin{array}{l}\text { Serotonin 2a (5- } \\
\text { HT2a) receptor }\end{array}$ & HTR2A & CHEMBL224 & $\begin{array}{l}\text { Family A G } \\
\text { proteincoupled } \\
\text { receptor }\end{array}$ & 100 & $1689 / 119$ \\
\hline & $\begin{array}{l}\text { Dopamine D1 } \\
\text { receptor }\end{array}$ & DRD1 & CHEMBL2056 & $\begin{array}{l}\text { Family A G } \\
\text { proteincoupled } \\
\text { receptor }\end{array}$ & 100 & $244 / 14$ \\
\hline & $\begin{array}{l}\text { Dopamine D2 } \\
\text { receptor }\end{array}$ & DRD2 & CHEMBL217 & $\begin{array}{l}\text { Family A G } \\
\text { proteincoupled } \\
\text { receptor }\end{array}$ & 100 & $3894 / 335$ \\
\hline & $\begin{array}{l}\text { Dopamine D3 } \\
\text { receptor }\end{array}$ & DRD3 & CHEMBL234 & $\begin{array}{l}\text { Family A G } \\
\text { proteincoupled } \\
\text { receptor }\end{array}$ & 100 & $1715 / 60$ \\
\hline & $\begin{array}{l}\text { Dopamine D4 } \\
\text { receptor }\end{array}$ & DRD4 & CHEMBL219 & $\begin{array}{l}\text { Family A G } \\
\text { proteincoupled } \\
\text { receptor }\end{array}$ & 100 & $851 / 41$ \\
\hline & $\begin{array}{l}\text { Serotonin 2c (5- } \\
\text { HT2c) receptor }\end{array}$ & HTR2C & CHEMBL225 & $\begin{array}{l}\text { Family A G } \\
\text { proteincoupled } \\
\text { receptor }\end{array}$ & 100 & $649 / 41$ \\
\hline & $\begin{array}{l}\text { Serotonin } \\
\text { transporter }\end{array}$ & SLC6A4 & CHEMBL228 & $\begin{array}{l}\text { Electrochemical } \\
\text { transporter }\end{array}$ & 11.8 & $1598 / 275$ \\
\hline & HERG & $\mathrm{KCNH} 2$ & CHEMBL240 & $\begin{array}{l}\text { Voltage-gated } \\
\text { ion } \\
\text { channel }\end{array}$ & 100 & $1071 / 49$ \\
\hline & $\begin{array}{l}\text { Serotonin } 6 \text { (5- } \\
\text { HT6) receptor }\end{array}$ & HTR6 & CHEMBL3371 & $\begin{array}{l}\text { Family A G } \\
\text { proteincoupled } \\
\text { receptor }\end{array}$ & 100 & $600 / 59$ \\
\hline & $\begin{array}{l}\text { Serotonin } 7 \\
\text { HT7) receptor }\end{array}$ & HTR7 & CHEMBL3155 & $\begin{array}{l}\text { Family A G } \\
\text { proteincoupled } \\
\text { receptor }\end{array}$ & 11.8 & $842 / 22$ \\
\hline
\end{tabular}




\section{Conclusion}

On February 20, 2020, the clinical study of Leflunomide (FDA-approved DHODH inhibitor) was used in Phase-2 (240 patients) Covid-19 disease, however, results on 28 patients were recently shared as pre-print (Chictr2000030058). In the article published in Wuhan, China on March 12, 2020, it was announced that drugs that can suppress Sars-Cov-2 virus 10 times more effective than DHODH inhibitors such as Leflunomide and Teriflunomide were discovered. However, the structure of drugs S312 and S416 coded in this study has not been described. On April 28, the Phase-1 study started on 20 Covid-19 patients for the drug Leflunomide in the USA (ClinicalTrials Code: NCT04361214). Immun Therapeutics Company on April 22 proved that their medicines called IMU-838 are DHODH inhibitors. After their announcement that they will quickly try this drug in Covid-19 patients, in which they show that they have anti-viral and anti-inflammatory properties, Phase- 2 and Phase- 3 clinical studies were started in 600 patients in May 2020 (ClinicalTrials Code: NCT04379271).

The first clinical trial results of leflunomide (Chictr2000030058), an FDA-approved DHODH inhibitor, in Covid19 disease, Wang et al. (2020) published by pre-print ${ }^{90}$. In an open-label controlled study conducted in Wuhan between 13 March and 17 April, leflunomide was found to be an effective drug in Covid19 disease. 12 patients were determined as SOC (standart of care) group and 15 patients as SOC + leflunomide group. After 14 days, leflunomide treatment showed that patients returned to a highly negative rate compared to the SOC group ( $80 \%$ versus $\% 16.7$ SOC). In consequence of the study, no adverse effects or deaths were detected.

With the help of in silico analyzes, drug repurposing studies are increasing day by day, targeting such as Sars-Cov-2 virus spike protein structure or RNA polymerases ${ }^{35,91-95}$. However, considering that DHODH is a possible target for Covid19 treatement, not in silico analysis is available to our knowledge.

Here we have analyzed 7900 molecules with 3D structures for their putative binding at the active site of DHODH using docking analysis as a potential target candidate for Covid-19 treatment. Uniquely, we have provided a straight forward method to filter and identify the most probable antagonist candidates by repeating docking for several DHODH structures available. Any candidate that provided an affinity above the treshold is filtered until 28 FDA-approved and 79 clinically tested drugs were left. Next, the discovered drugs were analyzed using target prediction tools and the literature was scanned for their affect against Sars-Cov-2 virus. We have compared our candidates with FDA-approved DHODH inhibitor, Leflunomide. The only 
other FDA-approved DHODH inhibitor, Teriflunomide, was not seen necessary for comparision due to high similarity to leflunomide at the first place.

Ellinger B. et al. (2020) screened 5632 candidate drugs on caco-2 cells against Sars-cov-2 virus. The multikinase inhibitors Sorafenib and Regorafenib in our list have been stated in the study published as that study and are among the effective molecules against Sars-cov-2 virus ${ }^{95}$. In another study by Weston et al. (2020) published in another pre-print, 20 fda-approved drugs were analyzed against Sars-Cov-2 virus in vivo and in vitro. In this study, it is stated that imatinib plays a highly effective role against the virus with a selectivity index value of more than $9.5^{93}$.

The effect of Acalabrutinib, known as BTK (Bruton Tyrosine Kinase) inhibitor, which is one of the drugs that we have identified as a possible DHODH inhibitor in our list, has been clinically researched and published by M. Roschewski et al. (2020) on June $5{ }^{96}$. As a hypothesis, the researchers predicted that acalabrutinib's BTK inhibitor activity can prevent ARDS in covid19 disease by blocking cytokine release in macrophages. Along with acalabrutinib treatment, a significant increase was observed in the oxygen respiration capacities of the patients and dramatic decrease was detected in IL-6 levels. Researchers suggest that acalabrutinib can be used effectively to suppress inflammation.

A strudy published in 24th of July by Riva L. et al. (2020), is quite remarkable when compared to our own data. Researchers have created a library called ReFRAME, which consists of 12,000 FDA-approved drugs and others in clinical trials. Molecules with an effective $\mathrm{EC}_{50}$ value were selected, 21 were selected and 13 drugs were found to be effectively to suppress Sars-Cov-2 virus. When these experimentally identified drugs were compared to our findings, remarkable similarity can be seen. The fact that known target regions of these 13 selected molecules include serotonin and dopamine antagonists, coincides with the fact that 8 of 28 FDA approved drugs we have identified are too serotonin and dopamine antagonists. Especially, it was determined that Elopiprazole, a serotonin 1a-Dopamine D2 receptor antagonist, did not cause any changes in the number of cells by curb the infection in Vero6-Sars-Cov-2 infected cells at very low doses $\left(\mathrm{EC}_{50}: 1.6 \mu \mathrm{M}\right)$. Elopiprazole is not included in Drugbank and, ergo, this study. Another effective molecule found in the study, Apilimod, was found effective in Phase II clinical studies against diseases such as rheumotoid arthritis, common variable immune deficiency (CVID). In addition, it has been reported by researchers that this drug has been found to suppress reproduction of EBOV, Lassa virus, Marburg viruses in human cells. Apilimod showed similarities with serotonin $2 \mathrm{~b}-2 \mathrm{c}$ antagonists. It is noteworthy that the information obtained 
about the apilimod and the given effects are similar to the expected effects as a result of DHODH inhibition, raising the question whether, an interaction between DHODH and the apilimod exists. When we analyzed this drug, which was eliminated only after seventh docking analysis (against 6j3c, 2wv8, 3kvj, 3kvl, 4igh, 4jtu and finally 4zl1) showed affinity in a range of -11.0 and $-12.9 \mathrm{kcal} / \mathrm{mol}$ according to Autodock Vina. In accordance our extensive potential DHODH inhibitor screening shows strong association between serotonin-dopamine antagonists and possible DHODH inhibitors compared to this study ${ }^{97}$.

In summary, FDA approved drugs that may be more effective than Leflunomide were determined by molecular docking analysis. Target regions and structural similarities of these drugs with high binding energy are also discussed in detail. The similarities of Leflunomide drug structurally related to other oxidoreductase and dopamine, serotonin antagonists were analyzed.

Interestingly, it is quite remarkable that the drugs that show high binding energy against DHODH enzyme on our list have similarities to oxidoreductase inhibitors as well as the antigonist effects of dopamine and serotonin. We suggest that these drugs used for treatment of diseases such as schizophrenia and depression should be followed in Covid-19 patients. After determining the DHODH enzyme activation of 28 FDA approved drugs analyzed and determining cell culture Sars-Cov-2 virus activations, we recommend that the active drugs be tested clinically on Covid19 patients. 


\section{References}

1. Zhou, P. et al. A pneumonia outbreak associated with a new coronavirus of probable bat origin. Nature (2020) doi:10.1038/s41586-020-2012-7.

2. Lu, R. et al. Genomic characterisation and epidemiology of 2019 novel coronavirus: implications for virus origins and receptor binding. Lancet (2020) doi:10.1016/S01406736(20)30251-8.

3. Maxmen, A. More than 80 clinical trials launch to test coronavirus treatments. Nature (2020) doi:10.1038/d41586-020-00444-3.

4. Rabi, F. A., Al Zoubi, M. S., Al-Nasser, A. D., Kasasbeh, G. A. \& Salameh, D. M. Sars-cov-2 and coronavirus disease 2019: What we know so far. Pathogens 9, 1-14 (2020).

5. Wang, M. et al. Remdesivir and chloroquine effectively inhibit the recently emerged novel coronavirus (2019-nCoV) in vitro. Cell Res. 30, 269-271 (2020).

6. Murithi, J. M. et al. Combining Stage Specificity and Metabolomic Profiling to Advance Antimalarial Drug Discovery. Cell Chem. Biol. 27, 158-171.e3 (2020).

7. Vincent, M. J. et al. Chloroquine is a potent inhibitor of SARS coronavirus infection and spread. Virol. J. (2005) doi:10.1186/1743-422X-2-69.

8. Hoffmann, M. et al. The novel coronavirus 2019 (2019-nCoV) uses the SARScoronavirus receptor ACE2 and the cellular protease TMPRSS2 for entry into target cells. bioRxiv (2020) doi:10.1101/2020.01.31.929042.

9. Li, X., Geng, M., Peng, Y., Meng, L. \& Lu, S. Molecular immune pathogenesis and diagnosis of COVID-19. J. Pharm. Anal. 19, 1-7 (2020).

10. Imai, Y. et al. Angiotensin-converting enzyme 2 protects from severe acute lung failure. Nature (2005) doi:10.1038/nature03712.

11. Channappanavar, R. et al. Dysregulated Type I Interferon and Inflammatory Monocyte-Macrophage Responses Cause Lethal Pneumonia in SARS-CoV-Infected Mice. Cell Host Microbe (2016) doi:10.1016/j.chom.2016.01.007.

12. Channappanavar, R. et al. IFN-I response timing relative to virus replication 
determines MERS coronavirus infection outcomes. J. Clin. Invest. (2019) doi:10.1172/JCI126363.

13. Yang, Y. et al. The structural and accessory proteins M, ORF 4a, ORF 4b, and ORF 5 of Middle East respiratory syndrome coronavirus (MERS-CoV) are potent interferon antagonists. Protein Cell (2013) doi:10.1007/s13238-013-3096-8.

14. Wang, Y. et al. Remdesivir in adults with severe COVID-19: a randomised, doubleblind, placebo-controlled, multicentre trial. Lancet 395, 1569-1578 (2020).

15. Favalli, E. G. et al. COVID-19 infection and rheumatoid arthritis: Faraway, so close! Autoimmun. Rev. 102523 (2020) doi:10.1016/j.autrev.2020.102523.

16. Scott, D. L., Wolfe, F. \& Huizinga, T. W. J. Rheumatoid arthritis. in The Lancet (2010). doi:10.1016/S0140-6736(10)60826-4.

17. Zhang, W. et al. The use of anti-inflammatory drugs in the treatment of people with severe coronavirus disease 2019 (COVID-19): The experience of clinical immunologists from China. Clinical Immunology (2020) doi:10.1016/j.clim.2020.108393.

18. Breedveld, F. C. \& Dayer, J. M. Leflunomide: Mode of action in the treatment of rheumatoid arthritis. Ann. Rheum. Dis. 59, 841-849 (2000).

19. Löffler, M. \& Zameitat, E. Pyrimidine Biosynthesis and Degradation (Catabolism). in Encyclopedia of Biological Chemistry: Second Edition (2013). doi:10.1016/B978-0-12378630-2.00178-X.

20. Löffler, M., Carrey, E. A. \& Zameitat, E. Orotic Acid, More Than Just an Intermediate of Pyrimidine de novo Synthesis. Journal of Genetics and Genomics (2015) doi:10.1016/j.jgg.2015.04.001.

21. Sykes, D. B. The emergence of dihydroorotate dehydrogenase (DHODH) as a therapeutic target in acute myeloid leukemia. Expert Opin. Ther. Targets 22, 893-898 (2018).

22. Fitzpatrick, L. R. et al. 4SC-101, a novel immunosuppressive drug, inhibits IL-17 and attenuates colitis in two murine models of inflammatory bowel disease. Inflamm. Bowel Dis. (2010) doi:10.1002/ibd.21264. 
23. Fitzpatrick, L. R., Small, J. S., Doblhofer, R. \& Ammendola, A. Vidofludimus inhibits colonic interleukin-17 and improves hapten-induced colitis in rats by a unique dual mode of action. J. Pharmacol. Exp. Ther. (2012) doi:10.1124/jpet.112.192203.

24. Tan, J. L. et al. Stress from Nucleotide Depletion Activates the Transcriptional Regulator HEXIM1 to Suppress Melanoma. Mol. Cell (2016) doi:10.1016/j.molcel.2016.03.013.

25. Mascia, L., Turchi, G., Bemi, V. \& Ipata, P. L. Uracil salvage pathway in PC12 cells. Biochim. Biophys. Acta - Gen. Subj. (2000) doi:10.1016/S0304-4165(00)00139-2.

26. Sykes, D. B. et al. Inhibition of Dihydroorotate Dehydrogenase Overcomes Differentiation Blockade in Acute Myeloid Leukemia. Cell 167, 171-186.e15 (2016).

27. Lewis, T. A. et al. Development of ML390: A Human DHODH Inhibitor That Induces Differentiation in Acute Myeloid Leukemia. ACS Med. Chem. Lett. (2016) doi:10.1021/acsmedchemlett.6b00316.

28. Singh, A., Maqbool, M., Mobashir, M. \& Hoda, N. Dihydroorotate dehydrogenase: A drug target for the development of antimalarials. European Journal of Medicinal Chemistry (2017) doi:10.1016/j.ejmech.2016.09.085.

29. Chen, S. et al. Suppression of pyrimidine biosynthesis by targeting DHODH enzyme robustly inhibits rotavirus replication. Antiviral Res. 167, 35-44 (2019).

30. Wang, Q.-Y. et al. Inhibition of Dengue Virus through Suppression of Host Pyrimidine Biosynthesis. J. Virol. (2011) doi:10.1128/jvi.02510-10.

31. Mei-jiao, G. et al. Antiviral effects of selected IMPDH and DHODH inhibitors against foot and mouth disease virus. Biomed. Pharmacother. 118, 1-7 (2019).

32. Hoffmann, H. H., Kunz, A., Simon, V. A., Palese, P. \& Shaw, M. L. Broad-spectrum antiviral that interferes with de novo pyrimidine biosynthesis. Proc. Natl. Acad. Sci. U. S. A. (2011) doi:10.1073/pnas.1101143108.

33. Xiong, R. et al. Novel and potent inhibitors targeting DHODH, a rate-limiting enzyme in de novo pyrimidine biosynthesis, are broad-spectrum antiviral against RNA viruses including newly emerged coronavirus SARS-CoV-2. bioRxiv 2020.03.11.983056 (2020) doi:10.1101/2020.03.11.983056. 
34. Liu, Q. et al. Enhancing the Antiviral Efficacy of RNA-Dependent RNA Polymerase Inhibition by Combination with Modulators of Pyrimidine Metabolism. Cell Chem. Biol. 27, 668-677.e9 (2020).

35. Xiong, R. et al. Novel and potent inhibitors targeting DHODH, a rate-limiting enzyme in de novo pyrimidine biosynthesis, are broad-spectrum antiviral against RNA viruses including newly emerged coronavirus SARS-CoV-2. bioRxiv (2020) doi:10.1101/2020.03.11.983056.

36. Wishart, D. S. et al. DrugBank 5.0: A major update to the DrugBank database for 2018. Nucleic Acids Res. (2018) doi:10.1093/nar/gkx1037.

37. O'Boyle, N. M. et al. Open Babel: An Open chemical toolbox. J. Cheminform. (2011) doi:10.1186/1758-2946-3-33.

38. Berman, H., Henrick, K. \& Nakamura, H. Announcing the worldwide Protein Data Bank. Nature Structural Biology (2003) doi:10.1038/nsb1203-980.

39. Fritzson, I. et al. Inhibition of human dhodh by 4-hydroxycoumarins, fenamic acids, and n-(alkylcarbonyl)anthranilic acids identified by structure-guided fragment selection. ChemMedChem (2010) doi:10.1002/cmdc.200900454.

40. McLean, L. R. et al. Discovery of novel inhibitors for DHODH via virtual screening and X-ray crystallographic structures. Bioorganic Med. Chem. Lett. (2010) doi:10.1016/j.bmcl.2010.01.115.

41. Das, P. et al. SAR-based optimization of a 4-quinoline carboxylic acid analogue with potent antiviral activity. ACS Med. Chem. Lett. (2013) doi:10.1021/ml300464h.

42. RCSB PDB - 4JTU: Crystal structure of human dihydroorotate dehydrogenase (DHODH) with brequinar analogue. https://www.rcsb.org/structure/4JTU.

43. RCSB PDB - 4ZL1: Crystal structure of human dihydroorotate dehydrogenase (DHODH) with 18X at 1.86 A resolution. https://www.rcsb.org/structure/4ZL1.

44. RCSB PDB - 4ZMG: Crystal structure of Human Dihydroorotate Dehydrogenase (DHODH) with DH03A338. https://www.rcsb.org/structure/4ZMG.

45. RCSB PDB - 5H2Z: Crystal structure of Human Dihydroorotate Dehydrogenase (DHODH) with 7GF. https://www.rcsb.org/structure/5H2Z. 
46. RCSB PDB - 5H73: Crystal structure of human DHODH with 18F. https://www.rcsb.org/structure/5H73.

47. RCSB PDB - 5HQE: Crystal structure of human dihydroorotate dehydrogenase (DHODH) with compound 18T. https://www.rcsb.org/structure/5HQE.

48. Sainas, S. et al. Design, synthesis, biological evaluation and X-ray structural studies of potent human dihydroorotate dehydrogenase inhibitors based on hydroxylated azole scaffolds. Eur. J. Med. Chem. (2017) doi:10.1016/j.ejmech.2017.02.017.

49. RCSB PDB - 6IDJ: Crystal structure of human DHODH in complex with ferulenol. https://www.rcsb.org/structure/6IDJ.

50. Zeng, T. et al. A novel series of human dihydroorotate dehydrogenase inhibitors discovered by in vitro screening: inhibition activity and crystallographic binding mode. FEBS Open Bio (2019) doi:10.1002/2211-5463.12658.

51. RCSB PDB - 6JMD: Crystal structure of human DHODH in complex with inhibitor 1223. https://www.rcsb.org/structure/6JMD.

52. RCSB PDB - 6LZL: Crystal structure of human dihydroorotate dehydrogenase (DHODH) with Piperine. https://www.rcsb.org/structure/6LZL.

53. Holm, L. \& Elofsson, A. Benchmarking fold detection by DaliLite v.5. Bioinformatics (2019) doi:10.1093/bioinformatics/btz536.

54. Morris, G. M. et al. Autodock4 and AutoDockTools4: automated docking with selective receptor flexiblity. J. Comput. Chem. (2009).

55. Trott, O. \& Olson, A. J. AutoDock Vina: Improving the speed and accuracy of docking with a new scoring function, efficient optimization, and multithreading. J. Comput. Chem. (2009) doi:10.1002/jcc.21334.

56. Daina, A., Michielin, O. \& Zoete, V. SwissTargetPrediction: updated data and new features for efficient prediction of protein targets of small molecules. Nucleic Acids Res. 47, W357-W3664 (2019).

57. Parasuraman, S. Prediction of activity spectra for substances. J. Pharmacol. Pharmacother. 2, 52-53 (2011).

58. Abdelgalil, A. A., Alkahtani, H. M. \& Al-Jenoobi, F. I. Sorafenib. in Profiles of Drug 
Substances, Excipients and Related Methodology (2019).

doi:10.1016/bs.podrm.2018.11.003.

59. Wilhelm, S. M. et al. Preclinical overview of sorafenib, a multikinase inhibitor that targets both Raf and VEGF and PDGF receptor tyrosine kinase signaling. Molecular Cancer Therapeutics (2008) doi:10.1158/1535-7163.MCT-08-0013.

60. Bruix, J. et al. Regorafenib for patients with hepatocellular carcinoma who progressed on sorafenib treatment (RESORCE): a randomised, double-blind, placebo-controlled, phase 3 trial. Lancet (2017) doi:10.1016/S0140-6736(16)32453-9.

61. Li, J. et al. Regorafenib plus best supportive care versus placebo plus best supportive care in Asian patients with previously treated metastatic colorectal cancer (CONCUR): A randomised, double-blind, placebo-controlled, phase 3 trial. Lancet Oncol. (2015) doi:10.1016/S1470-2045(15)70156-7.

62. Roskoski, R. Properties of FDA-approved small molecule protein kinase inhibitors: A 2020 update. Pharmacological Research (2020) doi:10.1016/j.phrs.2019.104609.

63. Tap, W. D. et al. Pexidartinib versus placebo for advanced tenosynovial giant cell tumour (ENLIVEN): a randomised phase 3 trial. Lancet (2019) doi:10.1016/S01406736(19)30764-0.

64. Baltschukat, S. et al. Capmatinib (INC280) is active against models of non-small cell lung cancer and other cancer types with defined mechanisms of MET activation. Clin. Cancer Res. (2019) doi:10.1158/1078-0432.CCR-18-2814.

65. Wolf, J. et al. Capmatinib (INC280) in MET $\Delta$ ex14 -mutated advanced non-small cell lung cancer (NSCLC): Efficacy data from the phase II GEOMETRY mono-1 study. . $J$. Clin. Oncol. (2019) doi:10.1200/jco.2019.37.15_suppl.9004.

66. Beck, B. R., Shin, B., Choi, Y., Park, S. \& Kang, K. Predicting commercially available antiviral drugs that may act on the novel coronavirus (SARS-CoV-2) through a drugtarget interaction deep learning model. Comput. Struct. Biotechnol. J. (2020) doi:10.1016/j.csbj.2020.03.025.

67. Raffi, F. et al. Once-daily dolutegravir versus twice-daily raltegravir in antiretroviralnaive adults with HIV-1 infection (SPRING-2 study): 96 week results from a randomised, double-blind, non-inferiority trial. Lancet Infect. Dis. (2013) 
doi:10.1016/S1473-3099(13)70257-3.

68. Blanco, J. L. et al. COVID-19 in patients with HIV: clinical case series. The Lancet HIV (2020) doi:10.1016/S2352-3018(20)30111-9.

69. Kahn, S. E. et al. Glycemic durability of rosiglitazone, metformin, or glyburide monotherapy. N. Engl. J. Med. (2006) doi:10.1056/NEJMoa066224.

70. Nauck, M. A. et al. Dapagliflozin versus glipizide as add-on therapy in patients with type 2 diabetes who have inadequate glycemic control with metformin: A randomized, 52-week, double-blind, active-controlled noninferiority trial. Diabetes Care (2011) doi:10.2337/dc11-0606.

71. Neal, B. et al. Canagliflozin and cardiovascular and renal events in type 2 diabetes. $N$. Engl. J. Med. (2017) doi:10.1056/NEJMoa1611925.

72. Khokhar, M. A. \& Rathbone, J. Droperidol for psychosis-induced aggression or agitation. Cochrane Database of Systematic Reviews (2016) doi:10.1002/14651858.CD002830.pub3.

73. Lieberman, J. A. et al. Effectiveness of antipsychotic drugs in patients with chronic schizophrenia. N. Engl. J. Med. (2005) doi:10.1056/NEJMoa051688.

74. Barone, J. A. Domperidone: A peripherally acting dopamine2-receptor antagonist. Annals of Pharmacotherapy (1999) doi:10.1345/aph.18003.

75. Burris, K. D. et al. Aripiprazole, a novel antipsychotic, is a high-affinity partial agonist at human dopamine D2 receptors. J. Pharmacol. Exp. Ther. (2002) doi:10.1124/jpet.102.033175.

76. Hirsch, L. E. \& Pringsheim, T. Aripiprazole for autism spectrum disorders (ASD). Cochrane Database of Systematic Reviews (2016) doi:10.1002/14651858.CD009043.pub3.

77. Hough, D. et al. Paliperidone palmitate maintenance treatment in delaying the time-torelapse in patients with schizophrenia: A randomized, double-blind, placebo-controlled study. Schizophr. Res. (2010) doi:10.1016/j.schres.2009.10.026.

78. Kasper, S., Möller, H. J. \& Hale, A. The European post-marketing observational sertindole study: An investigation of the safety of antipsychotic drug treatment. Eur. 
Arch. Psychiatry Clin. Neurosci. (2010) doi:10.1007/s00406-009-0018-0.

79. Khan, A. et al. A randomized, double-blind, placebo-controlled, 8-week study of vilazodone, a serotonergic agent for the treatment of major depressive disorder. J. Clin. Psychiatry (2011) doi:10.4088/JCP.10m06596.

80. Fleischhacker, W. W. et al. Efficacy and safety of brexpiprazole (OPC-34712) as maintenance treatment in adults with schizophrenia: A randomized, double-blind, placebo-controlled study. Int. J. Neuropsychopharmacol. (2017) doi:10.1093/ijnp/pyw076.

81. Maeda, K. et al. Brexpiprazole I: In vitro and in vivo characterization of a novel serotonin-dopamine activity modulator. J. Pharmacol. Exp. Ther. (2014) doi:10.1124/jpet.114.213793.

82. Färkkilä, M. et al. Efficacy and tolerability of lasmiditan, an oral 5-HT 1F receptor agonist, for the acute treatment of migraine: A phase 2 randomised, placebo-controlled, parallel-group, dose-ranging study. Lancet Neurol. (2012) doi:10.1016/S14744422(12)70047-9.

83. Shajib, M. S. \& Khan, W. I. The role of serotonin and its receptors in activation of immune responses and inflammation. Acta Physiol. 213, 561-574 (2015).

84. Herr, N., Bode, C. \& Duerschmied, D. The Effects of Serotonin in Immune Cells. Frontiers in Cardiovascular Medicine (2017) doi:10.3389/fcvm.2017.00048.

85. Stratz, C., Anakwue, J., Bhatia, H., Pitz, S. \& Fiebich, B. L. Anti-inflammatory effects of 5-HT3 receptor antagonists in interleukin-1beta stimulated primary human chondrocytes. Int. Immunopharmacol. 22, 160-166 (2014).

86. Nau, F., Yu, B., Martin, D. \& Nichols, C. D. Serotonin 5-HT2A Receptor Activation Blocks TNF- $\alpha$ Mediated Inflammation In Vivo. PLoS One 8, 2-9 (2013).

87. Domínguez-Soto, Á. et al. Serotonin drives the acquisition of a profibrotic and antiinflammatory gene profile through the 5-HT7R-PKA signaling axis. Sci. Rep. 7, 1-15 (2017).

88. Kato, S. Role of serotonin 5-HT3 receptors in intestinal inflammation. Biol. Pharm. Bull. 36, 1406-1409 (2013). 
89. Andrade, C. Nonsteroidal anti-inflammatory drugs and 5-HT3 serotonin receptor antagonists as innovative antipsychotic augmentation treatments for schizophrenia. $J$. Clin. Psychiatry 75, 707-709 (2014).

90. Wang, Q. et al. Efficacy and Safety of Leflunomide for Refractory COVID-19: An Open-label Controlled Study. medRxiv 2020.05.29.20114223 (2020) doi:10.1101/2020.05.29.20114223.

91. Cheke, R. S. The Molecular Docking Study of Potential Drug Candidates Showing Anti-COVID-19 Activity by Exploring of Therapeutic Targets of SARS-CoV-2. Eurasian J. Med. Oncol. 4, 185-195 (2020).

92. Touret, F. et al. Identification of antiviral drug candidates against SARS-CoV-2 from FDA-approved drugs. bioRxiv 53, 2020.04.16.044016 (2020).

93. Weston, S., Haupt, R., Logue, J., Matthews, K. \& Frieman, M. FDA approved drugs with broad anti-coronaviral activity inhibit SARS-CoV-2 in vitro. bioRxiv (2020) doi:10.1101/2020.03.25.008482.

94. Katie Heiser ${ }^{+1}$, Peter F. McLean ${ }^{+1}$, Chadwick T. Davis ${ }^{+1}$, Ben Fogelson ${ }^{1}$, Hannah B. Gordon $^{1}$, Pamela Jacobson ${ }^{1}$, Brett Hurst ${ }^{2}$, Ben Miller ${ }^{1}$, Ronald W. Alfa ${ }^{1}$, Berton A. Earnshaw $^{1}$, Mason L. Victors ${ }^{1}$, Yolanda T. Chong ${ }^{1}$, Imran S. Haque ${ }^{1}$, Adeline S. Low ${ }^{1}$, C. C. G. Identification of potential treatments for COVID-19 through artificial intelligence-enabled phenomic analysis of human cells infected with SARS-CoV-2. J. Chem. Inf. Model. (2020) doi:10.1017/CBO9781107415324.004.

95. Ellinger B., Bojkova D., Zaliani A., Cinatl J., Claussen C., Westhaus S., Reinshagen J., Kuzikov M., Wolf M., Geisslinger G., Gribbon P.,Ciesek S.,. Identification of inhibitors of SARS-CoV-2 in-vitro cellular toxicity in human (Caco-2) cells using a large scale drug repurposing collection. 1-19 (2020) doi:10.21203/RS.3.RS-23951/V1.

96. Roschewski, M. et al. Inhibition of Bruton tyrosine kinase in patients with severe COVID-19. Sci. Immunol. 5, 1-19 (2020).

97. Riva, L. et al. Discovery of SARS-CoV-2 antiviral drugs through large-scale compound repurposing. Nature (2020) doi:10.1038/s41586-020-2577-1. 